\title{
ASTER Shell: a simple concept to significantly increase the plastic buckling strength of short cylinders subjected to combined external pressure and axial compression
}

\author{
Alain Combescure ${ }^{*^{*}}$ and Jean-Francois Jullien ${ }^{2}$
}

\author{
*Correspondence: \\ alain.combescure@insa-lyon. \\ $\mathrm{fr}$ \\ 1 SAFRAN-AREVA-Chair \\ LaMCOS UMR CNRS 5259, \\ INSA-LYON, Universite de \\ Lyon, 61 AV President Wilson, \\ 69621 Villeurbanne, France \\ Full list of author information \\ is available at the end of the \\ article
}

\begin{abstract}
This paper proposes a new type of shell, similar to a cylindrical shell, which has significantly higher buckling strength when subjected to an arbitrary combination of uniform external pressure and axial compression. The underlying principle consists in a slight modification of the perfect cylinder in order to counteract the natural deformations which get larger and larger and lead to the collapse of the structure. Such shells are called ASTER shells. The concept has been validated through experiments, then analyzed numerically in order to explain what was observed and to propose avenues for improvements. The shells were made of electrodeposited nickel. The material was characterized. The chosen specimens were carefully measured to characterize their thickness and initial imperfections, then tested under the various types of loading. Then they were analyzed using finite elements. Thus, we were able to compare the finite element predictions with the experimental results. This comparison shows that plasticity has a decisive influence on the critical load and that linear elastic dimensioning leads to a serious overestimation of the experimental critical load. Contrary to perfect cylindrical shells, this type of shell is not significantly affected by geometric imperfections: this is another advantage of this type of design. Finally, we propose a numerical analysis in order to optimize the choice of the shape and propose shapes which resist buckling much better than a smooth cylinder when subjected to uniform external pressure, axial compression or a combination of both.
\end{abstract}

Keywords: Plasticity, External pressure, Axial compression , Imperfections, Selfstiffening, Buckling, Finite elements, Tests, Plasticity, External pressure, Axial compression

\section{Background}

The buckling of thin cylinders under axial compression or external pressure has been studied for many years [1-20] and is now well-understood. Geometric imperfections play a major role in a shell's resistance to axial compression and, generally, a lesser role in its resistance to external pressure [21-37]. Fewer works can be found in the literature regarding the effect of plasticity on buckling [38-45]: plasticity plays an important role

\section{垈 Springer}

(c) 2015 Combescure and Jullien. This article is distributed under the terms of the Creative Commons Attribution 4.0 International License (http://creativecommons.org/licenses/by/4.0/), which permits unrestricted use, distribution, and reproduction in any medium, provided you give appropriate credit to the original author(s) and the source, provide a link to the Creative Commons license, and indicate if changes were made. 
in the case of thicker cylinders and, coupled with initial imperfections, is often responsible for the significant decrease in the critical loads observed experimentally. This type of structure is also sensitive to the care with which the boundary conditions are applied $[19,46]$. The effect of the model used for the boundary condition on the critical load is also well-known, but it is more difficult to determine, in each practical case, the exact boundary condition which should be chosen. The literature on the buckling strength under combined axial compression and external pressure is less extensive [47]. The objective of this work is to propose a metallic shell which can be manufactured easily and which, on the one hand, avoids the high sensitivity to imperfections of ordinary shells under axial compression while, on the other hand, having a much better resistance to external pressure. This leads to an alternative to the shell defined in $[48,49]$ by optimizing a NURBS surface. NURBS shells have better resistance to axial compression, but their resistance to external pressure has not been assessed. There is no theoretical study or experiment available for such shells when the material has the characteristic elasticplastic behavior of metals.

The paper is organized as follows: the first section describes the ASTER shell concept, the experiments and the results. The second section describes the numerical prediction of these experiments and compares the results with the experimental results. The third section explains how these shells can be optimized to achieve a high resistance to external pressure and a good resistance to axial compression.

\section{ASTER shells: concept and experiments}

This section presents the experimental buckling obtained with three types of shells subjected to uniform external pressure, axial compression or a combination of the two. The shells were either smooth cylinders (the reference shells) or ASTER shells.

\section{The ASTER shell concept}

The ASTER shell concept derives from the observation of the evolution of the surface of cylindrical shells under external pressure loading and axial compression during lab tests. It has been known for many years that geometric imperfections have a decisive effect on the buckling load. However, it is imperative to know the type of imperfection, how it originates and then evolves during the loading, and its effect on the critical load in order to determine a "shape", based on the cylindrical geometry of the shell, which would be less sensitive or more effective. The quality of the experiments on the buckling of cylindrical shells carried out at INSA Lyon [50-58] has led to the ability to obtain highly-reproducible experimental critical loads of over $85 \%$ of the theoretical critical load under axial compression and $95 \%$ of the theoretical critical load under external pressure. It is possible to greatly reduce the presence of geometric manufacturing imperfections in the shell, for example by using the technique of metal electrodeposition on a machined support which, afterwards, can be discarded without affecting the shell. However, the development of geometric imperfections due to the application of boundary conditions is unavoidable. These systematic imperfections have a typical shape and are identical to those which result from the application of a circumferential membrane stress. They lead to the development of a modal circumferential geometry which is distributed more or less homogeneously over the surface of the shell. In the best-case 
scenario, the maximum amplitude of the imperfections thus generated is $10-20 \%$ of the shell's thickness. Subsequently, these initial imperfections cause the whole shell to buckle according to a perfect shell buckling circumferential mode (n) which corresponds to the mode under external pressure. The amplitude of these imperfections increases with the solicitation of this mode (n). The underlying idea of the ASTER shell, which has the same characteristic dimension (mean radius $\mathrm{R}$, thickness $\mathrm{h}$, height $\mathrm{L}$ ) as the cylindrical reference shell, consists, based on this cylindrical geometry, in developing a deliberately "undulated" shape by means of $p$ small vaults. One chooses $\mathrm{p}=2 \mathrm{n}$. These $2 \mathrm{n}$ small vaults all have a concavity which points inward in order to prevent the inception and then the amplification of the modal geometry. The choice of these outward vaults was an a priori choice driven by the observation that the curvature of an "incoming" imperfection (pointing toward the center of the shell) tends to be more active than the curvature of an "outgoing" imperfection. Figure 1 illustrates the ASTER shell concept.

The ASTER shell thus defined is designated as VM $2 \mathrm{n}$ because it consists of $2 \mathrm{n}$ vaults. Thus, if the perfect cylindrical shell buckles along mode 10, the corresponding ASTER shell is denoted ASTER VM20 because it has 20 vaults. A vault consists in a circular arc of radius $r$ defined in relation to the height $d$ of the vault with respect to the perfect cylinder. Figure 2 defines the parameters of the vault. This choice of a shape was made in order to facilitate the manufacturing of such a shell.

\section{Manufacturing of the specimens}

The cylinders to be tested were produced by electrodeposition of electrolytic nickel onto a machined aluminum die (for the cylindrical shells) or an epoxy resin die in the desired shape (for the ASTER shell).

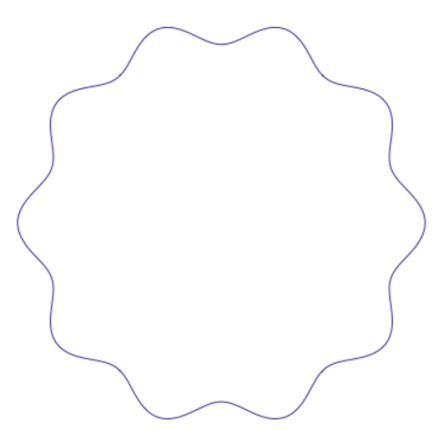

(a) Buckling mode 10

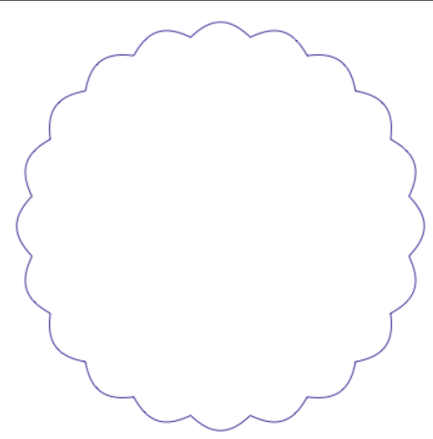

(b) ASTER VM20 shell

Fig. 1 The ASTER shell concept

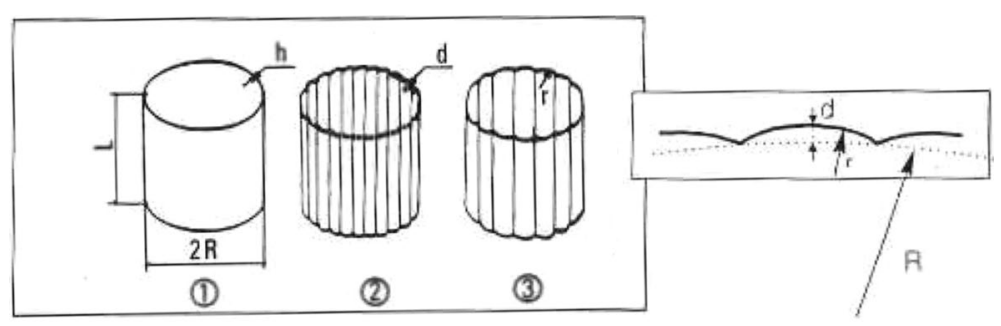

Fig. 2 ASTER shell: definition of $r$ and $d$ 
The die was cast into a mold which consisted of two machined duralumin half shells, then unmolded (Fig. 3).

Thus, it is possible to manufacture many dies of complex shapes from a single mold. Then, the external surface of the die is made conductive by spraying a thin layer of graphite. The die thus coated is immersed into a nickel sulfamate bath and subjected to a current. The immersion time and current intensity are the parameters which condition the thickness of the deposit. To ensure uniform thickness, the die is rotated in the bath. In addition, masks whose geometry is adjusted by trial-and-error are applied to complete the process. In order to extract the shell to be tested from the die without contact or mechanical actions which could create mechanical imperfections, the aluminum die is dissolved in caustic soda and the resin die is carved out from the inside and separated from the specimen. Finally, the ends are cut to shape by electroerosion to guarantee the quality of the supports and the perpendicularity with the axis of the shell. The thickness of the shell is quasi-constant, except that it is reduced by one-tenth along the vertical creases. It was assumed to be constant and equal to the average value for the purpose of the simulations. By design, these shells are very stiff with respect to circumferential modes 8-13: consequently, the roundness imperfections were negligible (less than onehundredth of the thickness). This procedure led to the manufacturing of "laboratory quality" shells.

\section{The test rig}

The shells were subjected to external pressure, axial compression or a combination of both. The experimental behavior was monitored throughout the experiment by a computer which recorded and processed the desired readings. The axial compressive load and the external pressure were displacement-controlled. At times, the load was sustained in order to allow the radial and axial deformations to be measured.

The global or partial geometry of the shell was measured in its initial state, at several loading levels and, finally, in its post-critical state. In order to do that, a contactless sensor moving circumferentially and axially was used to measure the evolution of the radius of a point of the internal surface. In addition, the normal displacement of a point

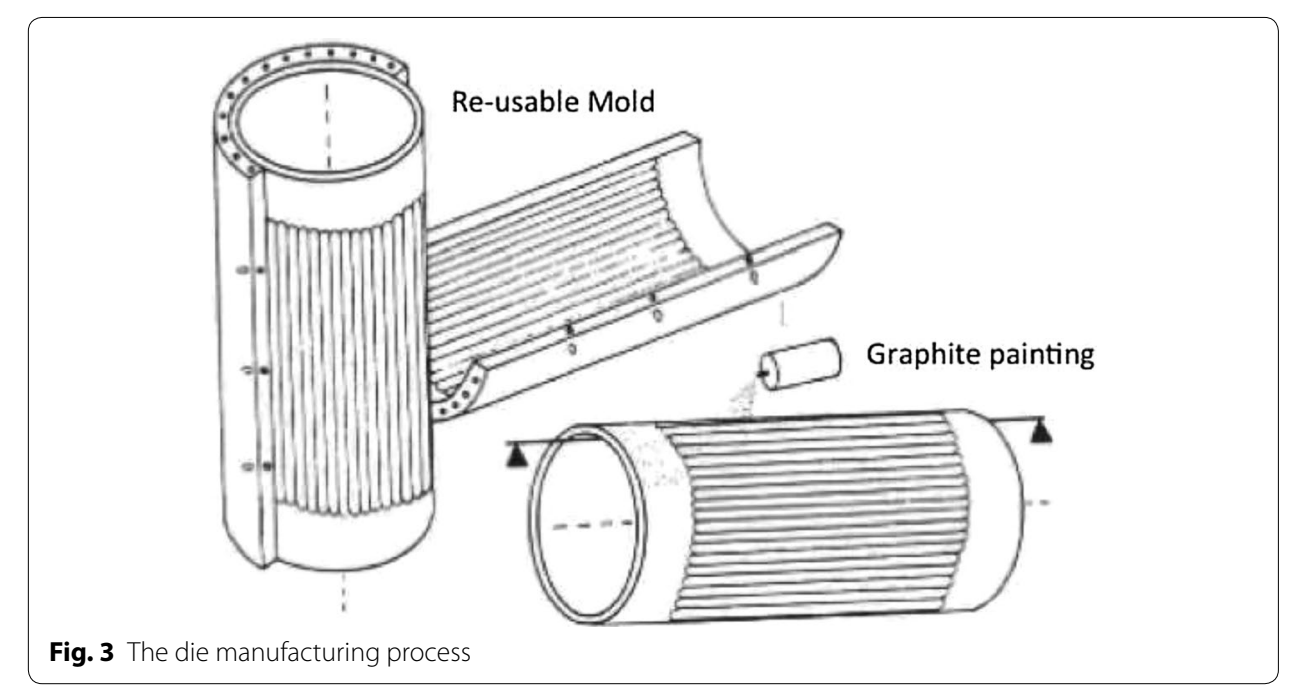


of the shell was monitored continuously throughout the loading. The chosen point was that which experienced the largest "incoming" displacement during a preloading step at about $15 \%$ of the expected critical pressure. This measurement was used to analyze the loading-radial displacement function and to anticipate the imminent occurrence of buckling.

\section{The geometry of the cylindrical shells}

The smooth shells studied were cylinders of average radius $R=75 \mathrm{~mm}$ and nominal length $L=120 \mathrm{~mm}$. Their average nominal thickness was about $150 \mu \mathrm{m}$. The ASTER shells were all generated from the same reference smooth shell (same base radius $R$, same length $L$ and same theoretical thickness $h$ ). Each specimen was measured. The thickness was measured by ultrasound at 30 regularly-spaced points on the surface. The thicknesses were quasi-uniform and so, from now on, we will refer only to the average thickness. The initial and post-critical geometries were obtained through the acquisition of 5000 points on the surface, taken along 34 regularly-spaced parallels. The variations in radius were measured along three parallels at one-degree intervals along the circumference, for each specimen and several loading levels (which remained constant during the measurement). Then, the variations of the average radius were decomposed using Fourier series expansion. The maximum amplitude of the initial shape imperfection of all the smooth shells (measured on Fourier modes 9, 10, 11, 12, 13, which were close to buckling mode 11) did not exceed $20 \%$ of the thickness. A typical post-critical geometry of a smooth shell under external pressure is shown in Fig. 4.

\section{Material properties}

The material properties were measured for each specimen. In order to do that, a tensile test piece was cut out of scrap material from a specimen and used to determine the Young's modulus and nonlinear properties (see Fig. 5).

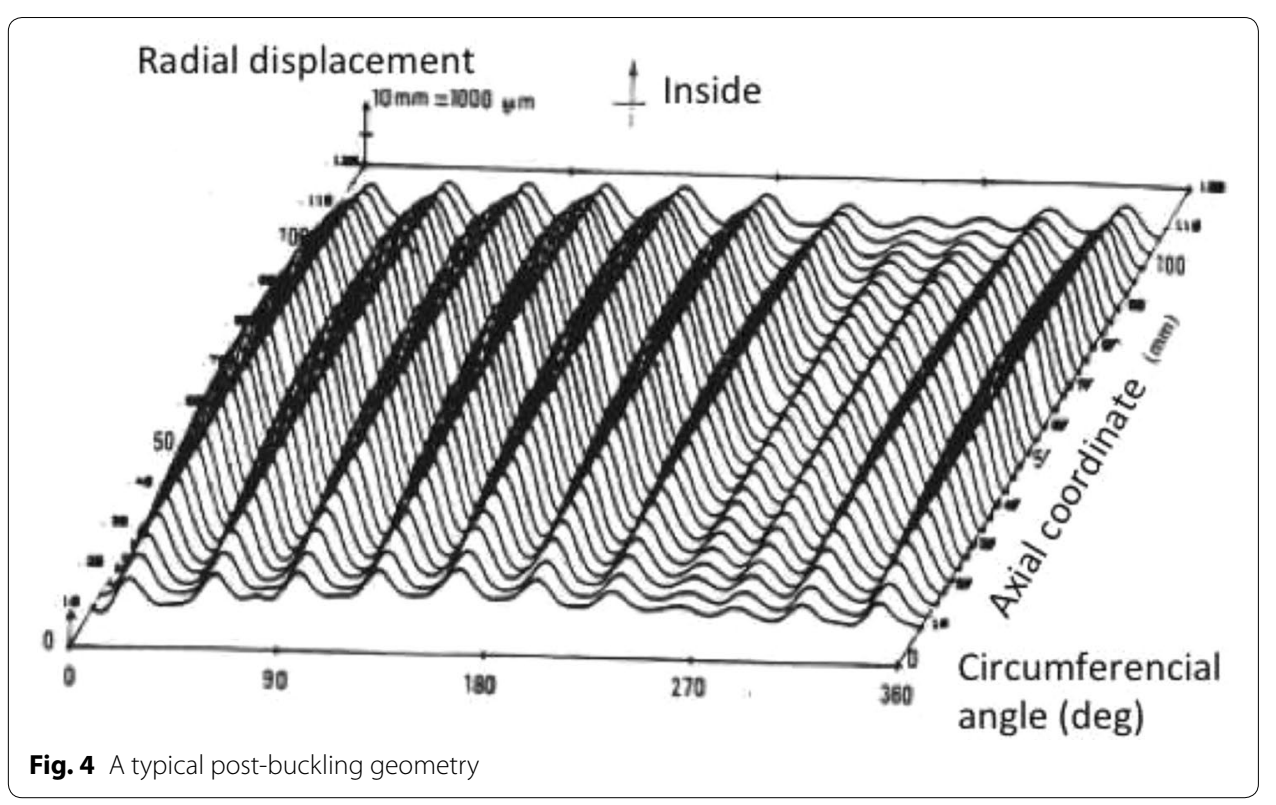




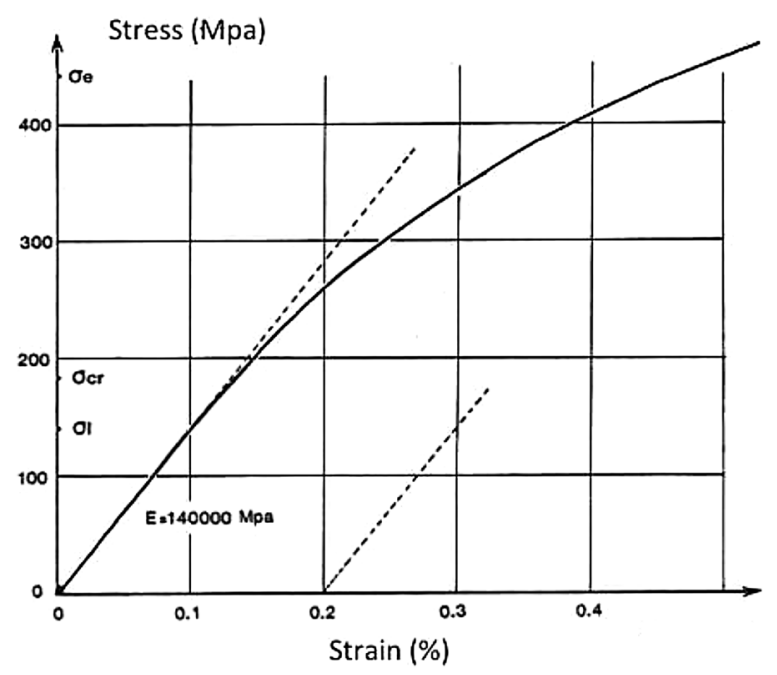

Fig. 5 A typical stress-strain curve

One can observe that the material ceases to be linear after a very small strain (0.001), after which the tangent modulus diminishes very progressively. This type of behavior is characteristic of many austenitic steels. We will see further on that taking this effect into account is very important for an accurate prediction of buckling.

\section{Experimental results}

A number of shells were tested under external pressure alone and under axial compression alone. Then, we tested their buckling strength under combined loading. We will present the experimental results obtained with cylindrical shells and then with two types of ASTER shells. These shells are usually characterized by their Batdorf parameter Z $\left(Z=\frac{L^{2}}{R h} \sqrt{1-v^{2}}\right.$, where $v$ denotes Poisson's coefficient).

For each shell studied, let us define a reference shell which is the smooth cylindrical shell of radius $R=75 \mathrm{~mm}$, length $L=120 \mathrm{~mm}$ and thickness $\mathrm{h}$ equal to the thickness measured on the shell being considered. This shell has the same Young's modulus as that measured on the specimen, is built-in at the base and has all its degrees of freedom (translation and rotation) along the upper circle set to zero, except for the axial displacement. We carried out a Fourier series analysis of this reference cylinder using truncated conical finite elements [58] (a mesh of 40 truncated conical elements is more than sufficient) in order to determine two reference critical loads: the critical elastic buckling pressure $P_{E}$ and the elastic buckling load under uniform axial compression $F_{E}$. These two quantities were used systematically to normalize all the results.

\section{The case of cylindrical shells}

The characteristics of each shell and the test results for the various smooth shells subjected to the simple load cases are given in Table 1 .

\section{The case of ASTER VM22 shells}

The experimental observations showed that the critical circumferential mode was mainly mode 11. Therefore, we manufactured a VM22-type shell consisting of 22 vaults with their 
Table 1 Characteristics of the cylinders and experimental buckling loads

\begin{tabular}{|c|c|c|c|c|}
\hline External pressure & A1 & $A 2$ & $\mathrm{A3}$ & A4 \\
\hline$h(\mu m)$ & 150 & 150 & 154 & 158 \\
\hline$R / h$ & 500 & 500 & 487 & 475 \\
\hline Z & 1220 & 1220 & 1190 & 1160 \\
\hline $\mathrm{E}(\mathrm{GPa})$ & 162 & 155 & 158 & 152 \\
\hline$P_{\exp }$ Buckling pressure (MPa) & 0.021 & 0.019 & 0.020 & 0.0223 \\
\hline$P_{E}(\mathrm{MPa})$ & 0.0213 & 0.0204 & 0.0222 & 0.0227 \\
\hline & 0.986 & 0.931 & 0.900 & 0.982 \\
\hline Fourier mode $n$ & 11 & 10 & 11 & 11 \\
\hline Axial compression & \multicolumn{3}{|c|}{ A5 } & A6 \\
\hline $\mathrm{h}(\mu \mathrm{m})$ & \multicolumn{3}{|c|}{150} & 148 \\
\hline$R / h$ & \multicolumn{3}{|c|}{500} & 500 \\
\hline Z & \multicolumn{3}{|c|}{1220} & 1933 \\
\hline $\mathrm{E}(\mathrm{GPa})$ & \multicolumn{3}{|c|}{163} & 155 \\
\hline$F_{\text {exp }}$ Buckling load (N) & \multicolumn{3}{|c|}{11,000} & 9275 \\
\hline$F_{E}(\mathrm{~N})$ & \multicolumn{3}{|c|}{14,193} & 13,125 \\
\hline$\frac{F_{\exp }}{F_{E}}$ & \multicolumn{3}{|c|}{0.775} & 0.707 \\
\hline Fourier mode $n$ & \multicolumn{3}{|c|}{11} & 12 \\
\hline
\end{tabular}

concavity pointed inward. The depth $\mathrm{d}$ of the vaults was equal to $2.32 \mathrm{~mm}$, which corresponds to a radius of curvature $\mathrm{r}$ equal to $20 \mathrm{~mm}$. Such an amplitude leads to a "hump" amplitude between 4 and 5 times the shell's nominal thickness. Table 2 below summarizes the various tests and gives the buckling loads of the elementary loading cases. The loading cases are normalized to the linear elastic buckling load of the smooth cylinder with the same radius, height, thickness and material. We found that the ASTER VM22 shells were four times more resistant to external pressure than the corresponding smooth shells and that the theoretical critical load of the reference cylinder associated with the shell being studied could be reached thanks to the vaults. Thus, these vaults have a beneficial effect for all the loading cases and are very effective against external pressure.

Table 2 ASTER VM22 shells: characteristics and experimental buckling loads

\begin{tabular}{|c|c|c|c|c|}
\hline External pressure & B1 & B2 & B3* & B4* \\
\hline $\mathrm{h}(\mu \mathrm{m})$ & 152 & 155 & 150 & 150 \\
\hline$R / h$ & 493 & 484 & 500 & 500 \\
\hline $\mathrm{E}(\mathrm{GPa})$ & 147 & 161 & 164 & 167.5 \\
\hline$P_{\text {exp }}$ Buckling pressure (MPa) & 0.091 & 0.092 & 0.070 & 0.072 \\
\hline$P_{E}(\mathrm{MPa})$ & 0.0190 & 0.0230 & 0.0216 & 0.0220 \\
\hline$\frac{P_{\exp }}{P_{E}}$ & 4.57 & 4.00 & 3.24 & 3.27 \\
\hline Axial compression & \multicolumn{3}{|c|}{ B5 } & B6 \\
\hline$h(\mu \mathrm{m})$ & \multicolumn{3}{|c|}{153} & 150 \\
\hline$R / h$ & \multicolumn{3}{|c|}{490} & 500 \\
\hline $\mathrm{E}(\mathrm{GPa})$ & \multicolumn{3}{|c|}{162} & 163 \\
\hline$F_{\text {exp }}$ Buckling Load (N) & \multicolumn{3}{|c|}{14,400} & 13,200 \\
\hline$F_{E}(\mathrm{~N})$ & \multicolumn{3}{|c|}{14,200} & 14,067 \\
\hline$\frac{F_{\text {exp }}}{F_{E}}$ & \multicolumn{3}{|c|}{1.01} & 0.94 \\
\hline
\end{tabular}


Remark the critical loads of shells B3 and B4 under external loading are marked with an * because these two shells were subjected to about ten external pressure cycles at two-thirds of the expected critical load prior to continuing all the way through failure by buckling. This pre-cycling reduces the critical load without cycling by about $25 \%$. We will return to this point in the discussion of the numerical simulation and explain this observation.

Figure 6 shows a post-critical geometry in the case of external pressure loading alone.

\section{The case of ASTER VM14 shells}

In order to study the effect of the choice of the ASTER geometry on the increase in the critical load, we also manufactured ASTER VM14 shells with $\mathrm{p}=14$ vaults along the circumference. The depth $\mathrm{d}$ of these vaults was $2.35 \mathrm{~mm}$, which corresponds to a radius of curvature $\mathrm{r}$ equal to $35 \mathrm{~mm}$. These shells were tested only under simple loading. Table 3 summarizes

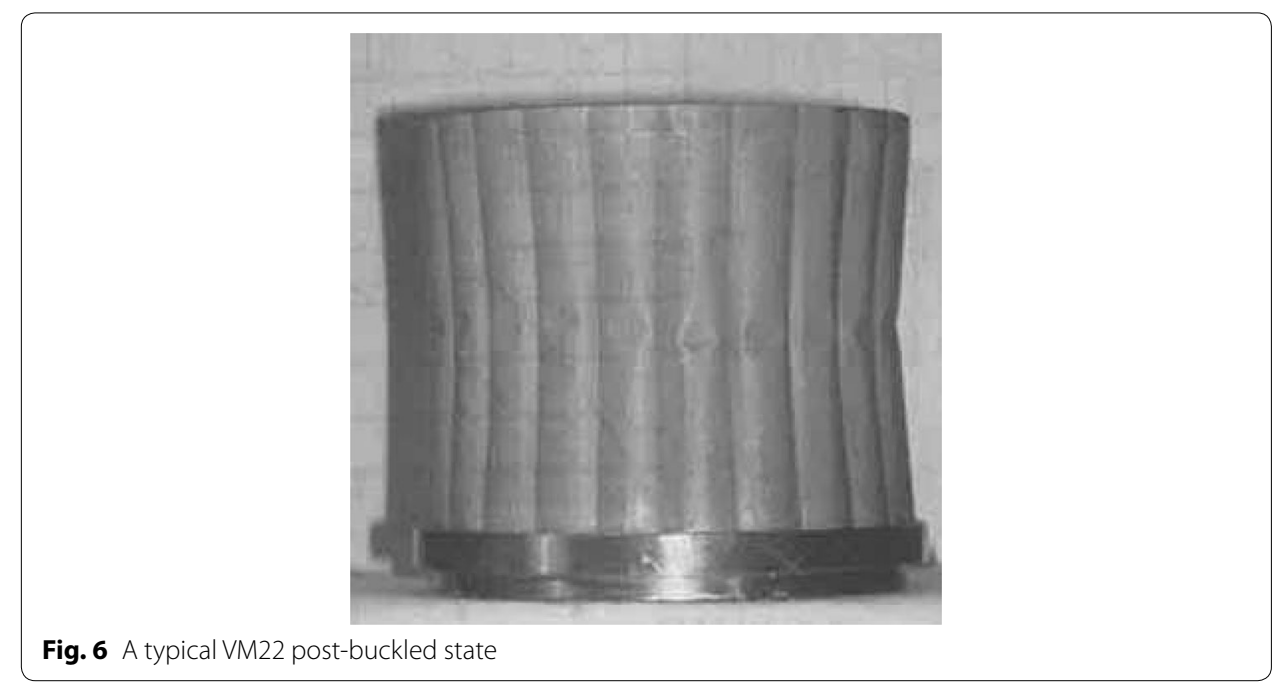

Table 3 ASTER VM14 shells: characteristics and experimental buckling loads

\begin{tabular}{lll}
\hline External pressure & C1 & C2 \\
\hline $\mathrm{h}(\mu \mathrm{m})$ & 149 & 147 \\
$\mathrm{R} / \mathrm{h}$ & 503 & 510 \\
$\mathrm{E}(\mathrm{GPa})$ & 154 & 143 \\
$P_{\exp }$ Buckling pressure $(\mathrm{MPa})$ & 0.054 & 0.045 \\
$P_{E}(\mathrm{MPa})$ & 0.020 & 0.018 \\
$P_{\text {exp }}$ & 2.7 & 2.6 \\
\hline$P_{E}$ & $\mathbf{C 3}$ & $\mathbf{C 4}$ \\
\hline xxial compression & 150 & 148 \\
$\mathrm{~h}(\mu \mathrm{m})$ & 500 & 507 \\
$\mathrm{R} / \mathrm{h}$ & 151 & 156.5 \\
$\mathrm{E}(\mathrm{GPa})$ & 6200 & 5100 \\
$F_{\exp }$ Buckling Load $(\mathrm{N})$ & 12937 & 13,012 \\
$F_{E}(\mathrm{~N})$ & 0.48 & 0.39 \\
$\frac{F_{\text {exp }}}{F_{E}}$ & & \\
\hline
\end{tabular}


the experimental results. One can immediately see that this type of vault is less effective under external pressure and cuts the critical load under axial compression in half.

A post-critical geometry under external pressure is shown in Fig. 7.

\section{The effects of loading combinations on buckling}

This section presents the effects of an interaction between loading cases on buckling for the first two shell types. In the case of combined loads, we increased the applied pressure and the axial compression load simultaneously. These two loading cases were apportioned to the reference linear buckling loads for the cylinder being considered. The results for smooth cylinders are given in Table 4 .

The results for VM22 shells are given in Table 5.

These results will be interpreted later with the presentation of the calculation results.

\section{Discussion of the experimental results}

The sum of these experimental results shows the interest of ASTER type shells in increasing buckling strength. One can see that the choice of the number of vaults plays an important role in the quality of the buckling strength. This type of shell, which can

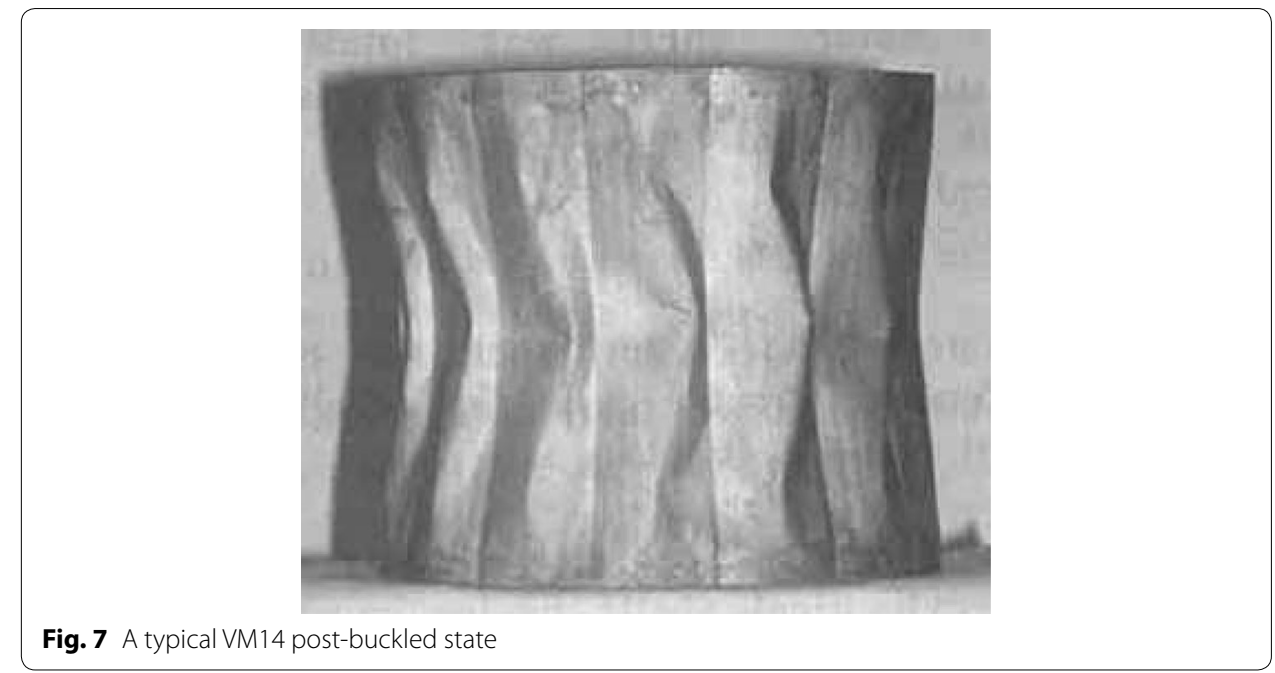

Table 4 Buckling under combined loading: characteristics of the cylinders and experimental buckling loads

\begin{tabular}{llllllll}
\hline Specimen & $\mathbf{h}(\boldsymbol{\mu} \mathbf{m})$ & $\mathrm{E}(\mathrm{GPa})$ & $\boldsymbol{P}_{\exp }(\mathrm{MPa})$ & $\boldsymbol{P}_{\exp }(\mathrm{N})$ & $\boldsymbol{P}_{E}(\mathrm{MPa})$ & $\boldsymbol{F}_{E}(\mathrm{~N})$ & Load ratio $\frac{F P_{E}}{F_{E} P}$ \\
\hline A1 & 150 & 163 & 0.021 & 0.000 & 0.0213 & 14,111 & 0 \\
A7 & 142 & 150 & 0.015 & 2000 & 0.0173 & 11,718 & 4 \\
A8 & 145 & 163 & 0.016 & 4500 & 0.0197 & 13,276 & 8 \\
A9 & 138 & 159 & 0.0131 & 3900 & 0.0171 & 11,737 & 8 \\
A10 & 148 & 155 & 0.012 & 6700 & 0.0197 & 13,150 & 16 \\
A11 & 139 & 156 & 0.0075 & 6800 & 0.0171 & 11,681 & 26 \\
A12 & 148 & 155 & 0.0078 & 7200 & 0.0197 & 13,150 & 26 \\
A13 & 137 & 160 & 0.0045 & 7800 & 0.0169 & 11,643 & 50 \\
A5 & 150 & 163 & 0.000 & 11,000 & 0.0214 & 14,193 & $\infty$ \\
\hline
\end{tabular}


Table 5 Buckling under combined loading: experimental buckling loads for VM22 ASTER shells

\begin{tabular}{llllllll}
\hline Specimen & $\mathbf{h}(\boldsymbol{\mu} \mathbf{m})$ & $\mathrm{E}(\mathrm{GPa})$ & $\boldsymbol{P}_{\exp }(\mathrm{MPa})$ & $\boldsymbol{F}_{\exp }(\mathrm{N})$ & $\boldsymbol{P}_{E}(\mathrm{MPa})$ & $\boldsymbol{F}_{E}(\mathrm{~N})$ & Load ratio $\frac{F}{F_{E}} \frac{P_{E}}{P}$ \\
\hline B2 & 150 & 161 & 0.0920 & 0 & 0.023 & 14,004 & 0 \\
B7 & 142 & 160 & 0.0543 & 2500 & 0.0184 & 12,314 & 0.7 \\
B8 & 140 & 148 & 0.0380 & 4500 & 0.0164 & 11,053 & 1.4 \\
B9 & 140 & 160 & 0.0326 & 7900 & 0.0177 & 11,951 & 1.8 \\
B10 & 152 & 163 & 0.0205 & 14,840 & 0.0221 & 14,337 & 3.5 \\
B5 & 153 & 162 & 0.000 & 14,200 & 0.0224 & 14,200 & $\infty$ \\
\hline
\end{tabular}

be manufactured easily, enables the resistance to buckling under external pressure to be quadrupled and makes the shell quasi-insensitive to imperfections under axial compression. This result is verified experimentally provided one chooses a number of vaults $\mathrm{p}$ equal to twice the critical number of circumferential waves in buckling (n). We will now attempt to understand why by means of a numerical simulation of these tests. Then, we will try to find a way to improve this design even further: in order to do that, we will attempt to predict the critical loads for a range of values of $\mathrm{p}$ through calculations. Thus, we will seek the existence of an optimum $\mathrm{p}$ for this type of shell subjected to combined load cases.

\section{The finite element model}

In this section, we undertake to model these tests using finite elements and compare the experimental results with these numerical simulations.

\section{Perfect cylindrical shells and ASTER shells}

First, we carried out two-node axisymmetric or quasi-axisymmetric finite element calculations of the smooth shells (using COMU axisymmetric elements with non-axisymmetric modal imperfections), then 3D calculations of the ASTER shells using DKT elements. In the latter case, a half-shell was meshed for each calculation. The base was built-in and the top of the cylinder was left free to dilate vertically. The remaining degrees of freedom of the circle were fixed. All the calculations were performed using the nonlinear finite element code Stanlax [58].

\section{The types of analyses performed}

For each cylinder, we first performed an elastic buckling analysis. Then we carried out different analyses depending on the case. For the smooth cylinders, we performed incremental, geometrically nonlinear axisymmetric analyses with elastic or elasticplastic behavior. We tested the possible loss of stability of the equilibrium thus obtained through a plastic bifurcation analysis on the Fourier modes [58]. For the 3D shells, we simply carried out a linear stability analysis followed by incremental, geometrically nonlinear, elastic and elastic-plastic analyses. We also tested the stability after each step of the nonlinear calculations. For all these calculations, we performed a convergence analysis. We found that 40 axisymmetric elements are more than sufficient for the critical loads to converge, and that 40 elements along the axis and 20 elements along the 
circumference are needed for the 3D calculation of each ASTER vault (which comes to 1600 DKT elements for each vault). The choice of the model for the nonlinear traction curve was important. We chose the same yield stress $\sigma_{y}=150 \mathrm{MPa}$ for all the calculations. The elastic-plastic behavior was given by the reference curve of Fig. 5 . The initial plastic strain was calculated by dividing the yield stress by the Young's modulus. The base of the cylinder was built-in for all the calculations. All the degrees of freedom of the upper circle were fixed, except for the axial displacement. This choice is consistent with the control of the experiments which nullified the end load associated with the pressure.

\section{Results of the calculations and comparison with the experimental results}

This section presents the results of the simulations and compares them to the experimental results.

\section{Cylindrical shells}

Let $P_{\text {exp }}$ and $F_{\text {exp }}$ be respectively the experimental buckling pressure in MPa and the experimental axial buckling load in N. $P_{E}$ and $F_{E}$ denote respectively the calculated linear elastic buckling pressure (taking into account the following forces and the axial compression load leading to Euler buckling). $P_{N L}$ and $P_{N L P}$ denote respectively the nonlinear elastic and nonlinear plastic buckling pressure. $F$ is the axial compression load. The plastic buckling loads were calculated using the tangent modulus theory.

\section{The case of perfect shells}

This section concerns simple external pressure or axial compression loading. The results of the calculations for perfect structures are compared to the experimental results for smooth cylinders A1-A6 in Table 6.

First, let us analyze the buckling pressure predictions. The linear buckling calculations predicted the experimental critical loads with less than $10 \%$ error in all cases. In two

Table 6 Perfect cylinders: experimental and calculated buckling loads

\begin{tabular}{lllll}
\hline External pressure & A1 & A2 & A3 & A4 \\
\hline$P_{\text {exp }}$ & 0.021 & 0.019 & 0.020 & 0.0223 \\
Fourier mode $n_{\exp }$ & 11 & 10 & 11 & 11 \\
$\frac{P_{\exp }}{P_{E}}$ & 0.986 & 0.931 & 0.900 & 0.982 \\
Fourier mode $n_{E}$ & 11 & 11 & 11 & 11 \\
$\frac{P_{\text {exp }}}{P_{N L}}$ & 0.991 & 0.920 & 0.900 & 0.982 \\
$\frac{P_{\text {exp }}}{P_{N L P}}$ & 0.991 & 0.920 & 0.900 & 0.982 \\
\hline Axial compression & & $\mathbf{A 5}$ & & $\mathbf{A 6}$ \\
\hline$F_{\exp }$ & 11,000 & & 9275 \\
Fourier mode $n_{\exp }$ & & 11 & 12 \\
$\frac{F_{\text {exp }}}{F_{E}}$ & & 0.775 & 0.707 \\
Fourier mode $n_{E}$ & $2-15$ & & $2-15$ \\
$\frac{F_{\text {exp }}}{F_{N L}}$ & 0.648 & 0.708 \\
$\frac{F_{\text {exp }}}{P_{N L P}}$ & 1.01 & & 0.919 \\
\hline
\end{tabular}


cases, the experimental load was predicted within less than $3 \%$. Buckling occurred in the elastic domain. There was no nonlinear pre-buckling effect.

The buckling calculations under axial compression clearly establish that plasticity is responsible for the experimental load being 30 \% less than the Euler load. In the case of pure axial compression, we found the same results as in the literature: a large number of Fourier modes correspond to the same critical load. The buckling modes for Fourier modes 0 and 11 are given in Fig. 8. Under uniform axial compression, the cylinder always buckles on mode 11. The corresponding shape is shown in Fig. 9.

\section{Influence of initial imperfections}

One can also consider the influence of initial imperfections on the critical load. In order to do that, we added an initial imperfection to the perfect geometry in the shape of the elastic buckling mode with amplitude $\delta$. Three cases were calculated $\left(\frac{\delta}{h}=0.2,0.1\right.$ and 0.01). The largest amplitude corresponds to the maximum imperfection measured on the specimens tested. The calculations were performed with COMU elements, which are specifically adapted to this approach [59]: the imperfection was monomodal on Fourier mode 11, and the response was decomposed according to Fourier modes 0, 11, 22 and 33. Plasticity was evaluated at 21 points along the circumference. Table 7 summarizes the results of the geometric and material nonlinear calculations for the three

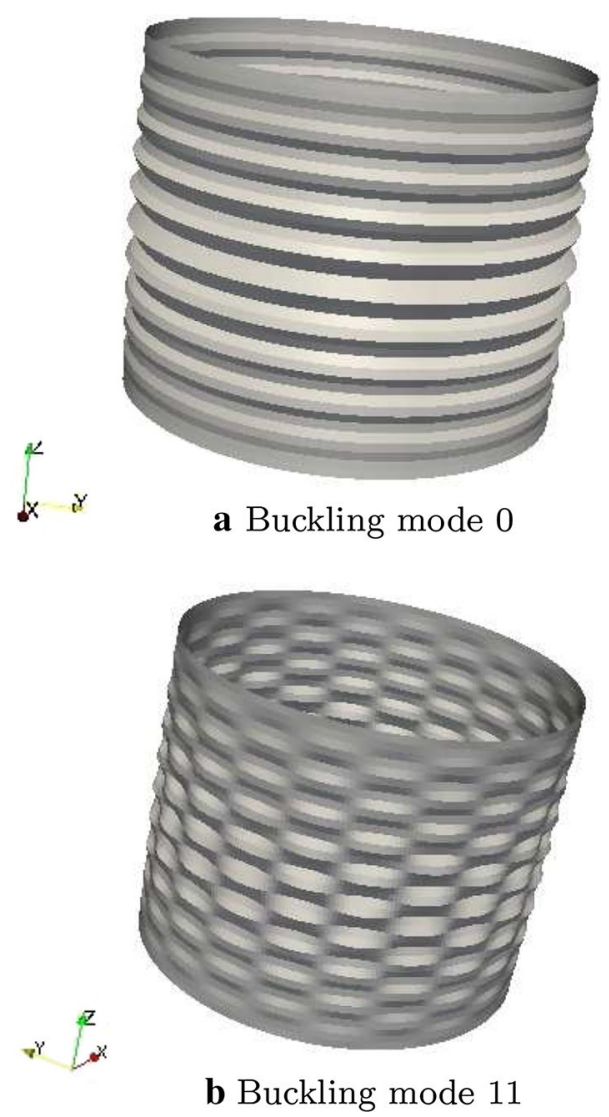

Fig. 8 Buckling modes under axial compression 


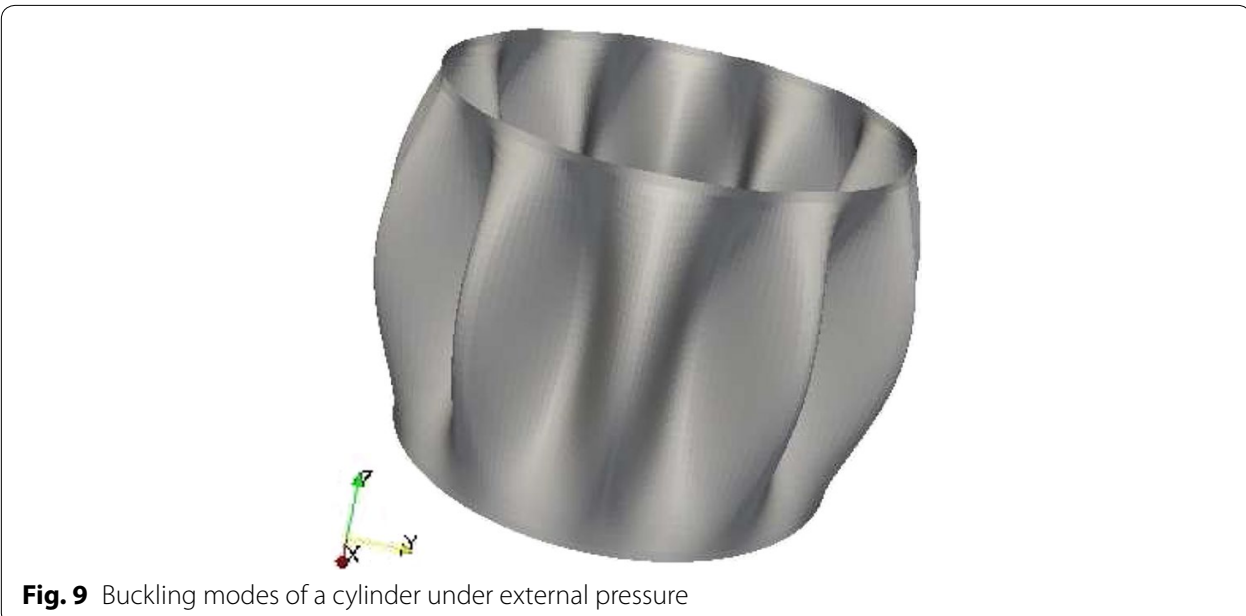

Table 7 Imperfect cylinders: experimental and calculated buckling loads

\begin{tabular}{|c|c|c|c|c|}
\hline External pressure & A1 & A2 & A3 & A4 \\
\hline$\frac{P_{\exp }}{P_{x}}$ & 0.991 & 0.920 & 0.900 & 0.982 \\
\hline$\frac{P_{\text {exp }}}{P_{N P C O M U}} ; \frac{\delta}{h}=0.01$ & 0.986 & 0.879 & 0.920 & 1.00 \\
\hline$\frac{P_{\exp }}{P_{\text {NLPCOMU }}} ; \frac{\delta}{h}=0.1$ & 1.06 & 0.937 & 0.985 & 1.069 \\
\hline$\frac{P_{\exp }}{P_{N L P C O M U}} ; \frac{\delta}{h}=0.2$ & 1.15 & 0.994 & 1.04 & 1.129 \\
\hline Axial compression & & A5 & & A6 \\
\hline$\frac{F_{\text {exp }}}{P_{N L P}}$ & & 1.01 & & 0.919 \\
\hline$\frac{F_{\text {exp }}}{F_{\text {NLPCOMU }}} ; \frac{\delta}{h}=0.01$ & & 1.076 & & 0.922 \\
\hline$\frac{F_{\text {exp }}}{F_{N L P C O M U}} ; \frac{\delta}{h}=0.1$ & & 1.080 & & 0.988 \\
\hline$\frac{F_{\text {exp }}}{F_{\text {NLPCOMU }}} ; \frac{\delta}{h}=0.2$ & & 1.087 & & 0.996 \\
\hline
\end{tabular}

imperfection amplitudes. Plasticity was not activated in the case of pressure loading, but only for axial compression.

These results show that with an amplitude of initial modal imperfections less than $20 \%$ of the thickness (which is consistent with our experiments) the calculations match the experimental results.

\section{Load interaction diagrams}

Let us now address the interactions between loading cases. In order to do that, we consider a reference shell with Young's modulus 160,000 Mpa and thickness $150 \mu \mathrm{m}$. With this cylinder, elastic buckling occurs at an external pressure $P_{E}$ equal to $0.02103 \mathrm{MPa}$, and at an axial compression load equal to $13,961 \mathrm{~N}$. We calculated the linear, elastic nonlinear and elastic-plastic nonlinear critical loads for six loading combinations. We also calculated the elastic-plastic nonlinear response with a modal imperfection parallel to the buckling mode shape under external pressure and an amplitude equal to 10 or $1 \%$ of the thickness for each case. Very similar results were obtained with a imperfection of the same amplitude, but parallel to the buckling mode under axial compression. Table 8 summarizes all the calculations. In this Table, $\Lambda_{E}$ is the multiplying coefficient of the 
Table 8 Buckling under combined loading: calculated ratios under various modeling assumptions

\begin{tabular}{lllllll}
\hline Pressure load ratio & Axial load ratio & $\boldsymbol{\Lambda}_{\boldsymbol{E}}$ & $\boldsymbol{\Lambda}_{\boldsymbol{N L}}$ & $\boldsymbol{\Lambda}_{\boldsymbol{N L P}}$ & $\boldsymbol{\Lambda}_{\boldsymbol{\delta}=0.01}$ & $\boldsymbol{\Lambda}_{\boldsymbol{\delta}=\mathbf{0 . 1}}$ \\
\hline 0.0 & 1.0 & 1.00 & 0.994 & 0.756 & 0.724 & 0.71 \\
0.2 & 0.8 & 1.17 & 1.171 & 0.944 & 0.960 & 0.895 \\
0.4 & 0.6 & 1.18 & 1.186 & 1.186 & 1.161 & 1.06 \\
0.6 & 0.4 & 1.14 & 1.146 & 1.146 & 1.107 & 1.102 \\
0.8 & 0.2 & 1.07 & 1.078 & 1.078 & 1.042 & 0.97 \\
1.0 & 0.0 & 1.00 & 1.01 & 1.01 & 0.99 & 0.92 \\
\hline
\end{tabular}

applied loading combination which leads to Euler buckling. Similarly, $\Lambda_{N L}$ and $\Lambda_{N L P}$ are the multiplying coefficients which lead to elastic and plastic nonlinear buckling, respectively. Coefficients $\Lambda_{\text {defa }=0.01}$ and $\Lambda_{\text {defa }=0.1}$ are the multiplying coefficients leading to the elastic-plastic buckling load for an initial imperfection of amplitude 0.01 and $0.1 \%$ of the thickness, respectively. These are compared with the experimental results obtained for shells A1, A5 and A7-A13. All these results are normalized to the Euler pressure in abscissa and the Euler axial compression load in ordinate. Table 9 gives the normalized experimental results. Figure 10 shows a comparison between the interaction diagram obtained from the calculations and the experimental data.

This figure shows good agreement between calculations and experimental results concerning the interaction diagram. In the case of significant axial compression loads, as noted previously, plasticity plays an important role. Conversely, it does not affect external pressure loading. All the interaction curves are convex. Therefore, a linear interaction is conservative, provided the critical load reduction effects on axial compression (plasticity) and on external pressure (geometric imperfections) are taken into account. For these tests, the calculations with an amplitude of initial modal imperfection equal to $10 \%$ of the thickness lead to a good estimate of the experimental critical load in all the cases.

The case of ASTER VM22 shells

In this section, we focus on the prediction of the critical load for ASTER VM22 shells (22 outward vaults). The results of the calculations for the "perfect" structure under simple

Table 9 Buckling under combined loading: Euler loads and experimental ratios

\begin{tabular}{lllll}
\hline Specimen & $P_{E}(\mathrm{MPa})$ & $\boldsymbol{F}_{E}(\mathrm{~N})$ & $\frac{P_{\exp }}{P_{E}}$ & $\frac{F_{\text {exp }}}{F_{E}}$ \\
\hline A1 & 0.0210 & 14,111 & 0.99 & 0.021 \\
A7 & 0.01725 & 11,718 & 0.87 & 0.17 \\
A8 & 0.01972 & 13,276 & 0.81 & 0.34 \\
A9 & 0.01707 & 11,737 & 0.76 & 0.33 \\
A10 & 13,150 & 0.61 & 0.51 \\
A11 & 11,680 & 0.44 & 0.58 \\
A12 & 0.01971 & 13,150 & 0.40 & 0.55 \\
A13 & 0.01704 & 11,643 & 0.27 & 0.67 \\
A5 & 0.01971 & 14,193 & 0.00 & 0.77 \\
\hline
\end{tabular}




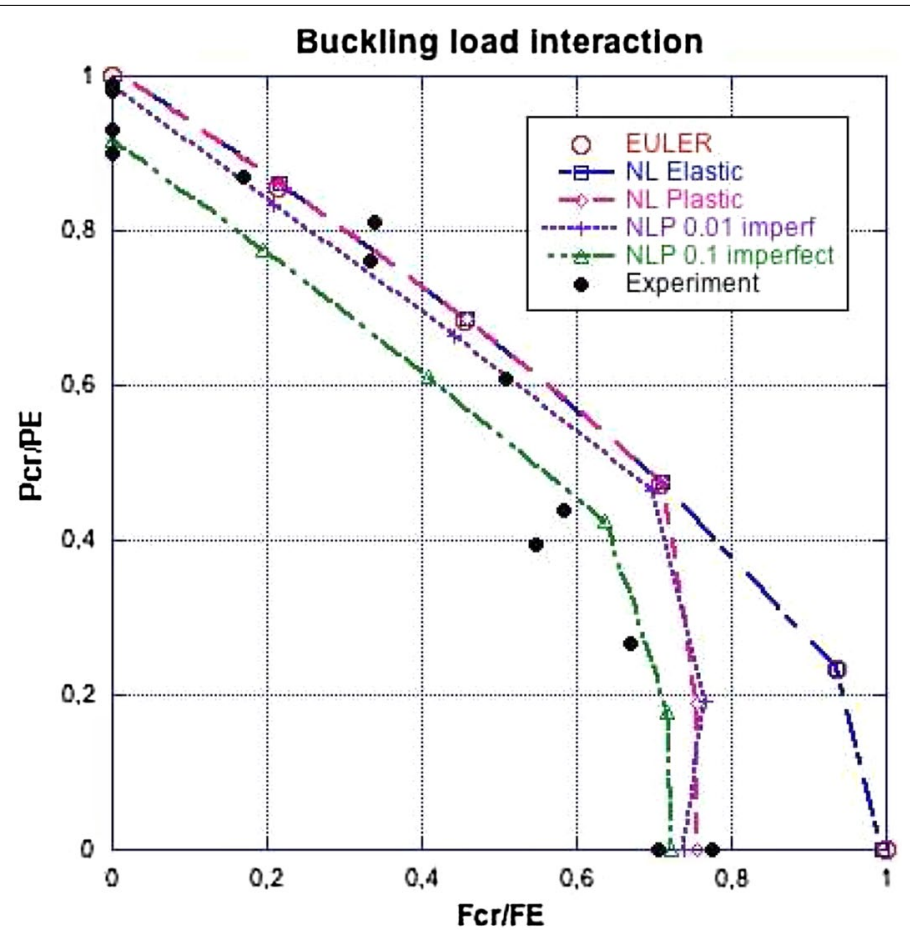

Fig. 10 Cylinders under combined loading (experiments and calculations): interaction diagram

pressure loading for shells B1 and B2 and under uniform axial compression for shell B5 are compared to the experimental results in Table 10.

The calculated predictions match the experimental results very well when plasticity is taken into account. The nonlinear elastic calculations systematically overestimate the critical loads. Two calculated buckling deformed shapes (under axial compression and under external pressure) are presented in Fig. 11. Now let us address combined loading. These cases concern the experiments on shells B1, B2, B7, B8, B9, B10 and B5. The theoretical loads are normalized to the Euler loads of the corresponding perfect cylindrical shells. The theoretical critical loads under combined loading were calculated with the same properties as the reference shell (Young's modulus 160,000 Mpa and thickness 150 $\mu \mathrm{m}$, as in the case of smooth cylinders) and divided by the elastic buckling loads of the same shell (Table 11).

The calculation results are given in Table 12 .

The results of the various calculations are compared with the experimental results in Fig. 12.

Table 10 ASTER VM22 shells: comparison of the calculated and experimental buckling loads

\begin{tabular}{llllll}
\hline Specimen & Loading type & Experimental buckling load & $\frac{\boldsymbol{\Lambda}_{\text {exp }}}{\boldsymbol{\Lambda}_{\boldsymbol{E}}}$ & $\frac{\boldsymbol{\Lambda}_{\text {exp }}}{\boldsymbol{\Lambda}_{\boldsymbol{N L}}}$ & $\frac{\boldsymbol{\Lambda}_{\text {exp }}}{\boldsymbol{\Lambda}_{\boldsymbol{N L P}}}$ \\
\hline B1 & Pressure & $0.091 \mathrm{MPa}$ & 4.57 & 0.58 & 1.01 \\
B2 & Pressure & $0.092 \mathrm{MPa}$ & 4.00 & 0.512 & 0.98 \\
B5 & Axial load & $14,200 \mathrm{~N}$ & 0.99 & 0.84 & 1.03 \\
\hline
\end{tabular}




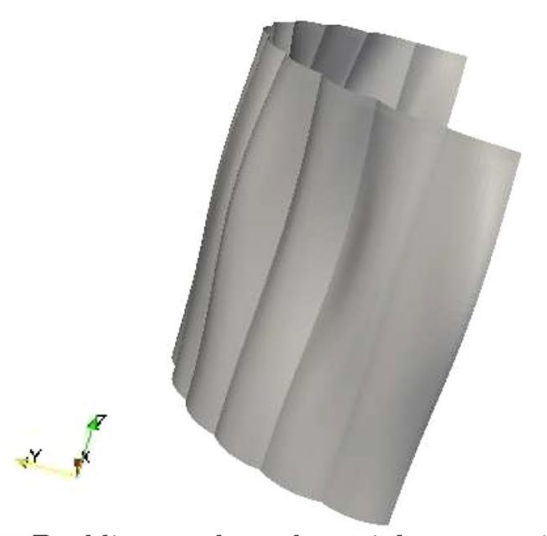

a Buckling mode under axial compression

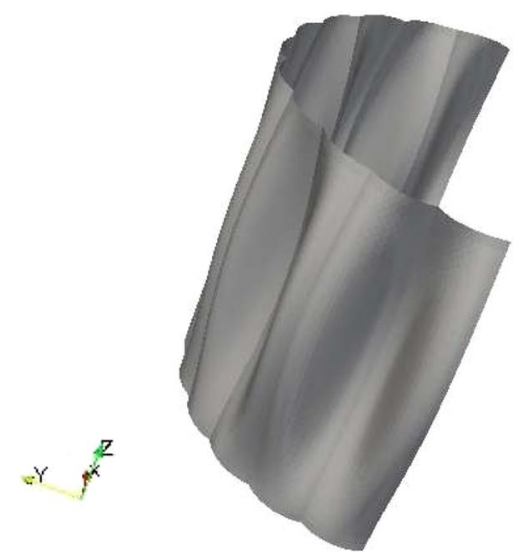

b Buckling mode under external pressure

Fig. 11 ASTER VM22 buckling modes

Table 11 ASTER VM22 shells: experimental buckling loads under combined loading

\begin{tabular}{lllll}
\hline Specimen & $P_{E}(\mathbf{M P a})$ & $F_{E}(\mathbf{N})$ & $\frac{P c r_{\text {exp }}}{P_{E}}$ & $\frac{F c r_{\text {exp }}}{F_{E}}$ \\
\hline B1 & 0.0199 & 13,171 & 4.57 & 0.00 \\
B2 & 0.023 & 14,972 & 4.00 & 0.00 \\
B7 & 0.0184 & 12,315 & 2.95 & 0.20 \\
B8 & 0.0164 & 11,053 & 2.32 & 0.41 \\
B9 & 0.0177 & 11,951 & 1.84 & 0.66 \\
B10 & 14,337 & 0.93 & 1.04 \\
B5 & 0.0221 & 14,400 & 0 & 1.01 \\
B6 & 0.021 & 14,119 & 0 & 0.99 \\
\hline
\end{tabular}

One can observe that in most cases a calculation based on linear elastic analysis is not predictive. The comparison with geometrically nonlinear calculations is even worse: in this case, the geometric nonlinearities have a stiffening effect. The only predictive calculation is the one which takes plasticity into account. This effect is drastic in almost all the cases: plasticity reduces the critical load by about one-third. In this type of stiffening effect, plasticity always plays an important role. 
Table 12 ASTER VM22 shell buckling under combined loading: calculated ratios under various modeling assumptions

\begin{tabular}{lllll}
\hline Pressure load ratio & Axial load ratio & $\boldsymbol{\Lambda}_{\boldsymbol{E}}$ & $\boldsymbol{\Lambda}_{\boldsymbol{N L}}$ & $\boldsymbol{\Lambda}_{\boldsymbol{N L P}}$ \\
\hline 0.0 & 1.0 & 1.60 & 0.95 & 0.84 \\
0.1 & 0.9 & 1.79 & 1.65 & 1.29 \\
0.2 & 0.8 & 2.03 & 1.80 & 1.36 \\
0.3 & 0.7 & 2.33 & 1.98 & 1.45 \\
0.4 & 0.6 & 2.75 & 2.27 & 1.57 \\
0.5 & 0.5 & 2.95 & 2.48 & 1.74 \\
0.6 & 0.4 & 3.06 & 2.83 & 1.95 \\
0.7 & 0.3 & 3.12 & 3.31 & 2.23 \\
0.8 & 0.2 & 3.16 & 3.92 & 2.60 \\
0.9 & 0.1 & 3.29 & 5.00 & 3.08 \\
1.0 & 0.0 & 3.31 & 5.95 & 4.01 \\
\hline
\end{tabular}

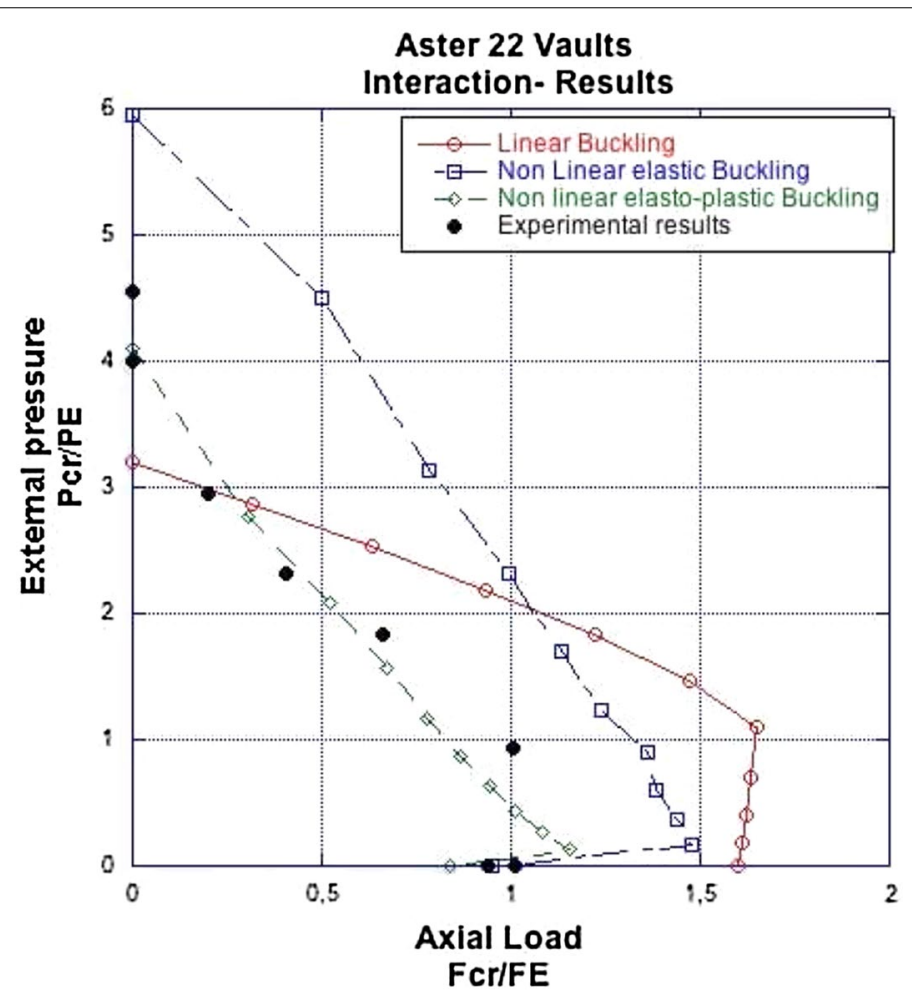

Fig. 12 ASTER VM22 shell under combined loading (experiments and predictions): interaction diagram

\section{The case of ASTER VM14 shells}

In this section, we focus on the numerical prediction of the tests for 14-vaulted shells. The results of the 3D calculations are compared to the experimental results in Table 13. Figure 13 shows the two elastic buckling modes. In this case in which the vaults lead to a less significant gain in critical load, the geometrically nonlinear predictions are good for the first three shells. The addition of plasticity slightly improves the results. For shell C4, 
Table 13 ASTER VM14 shells: comparison of the calculated and experimental buckling loads

\begin{tabular}{llllll}
\hline Specimen & Loading type & Experimental buckling load & $\frac{\boldsymbol{\Lambda}_{\text {exp }}}{\boldsymbol{\Lambda}_{\boldsymbol{E}}}$ & $\frac{\boldsymbol{\Lambda}_{\text {exp }}}{\boldsymbol{\Lambda}_{\boldsymbol{N L}}}$ & $\frac{\boldsymbol{\Lambda}_{\text {exp }}}{\boldsymbol{\Lambda}_{\boldsymbol{N L P}}}$ \\
\hline C1 & Pressure & $0.054 \mathrm{MPa}$ & 2.7 & 0.99 & 0.93 \\
C2 & Pressure & $0.046 \mathrm{MPa}$ & 2.6 & 0.85 & 0.87 \\
C3 & Axial load & $6200 \mathrm{~N}$ & 0.48 & 0.97 & 1.0 \\
C4 & Axial load & $5100 \mathrm{~N}$ & 0.39 & 0.78 & 0.83 \\
\hline
\end{tabular}

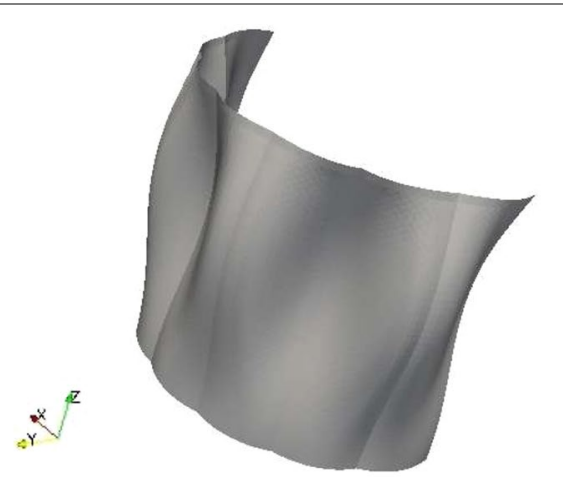

a Buckling mode under axial compression

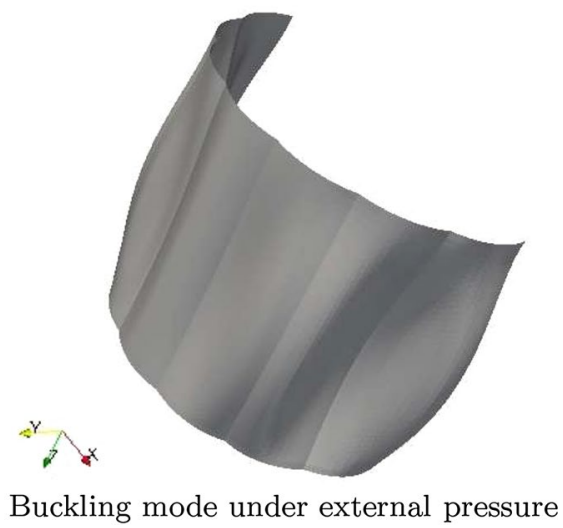

Fig. 13 ASTER VM14 buckling modes

which is subjected to axial compression, the predictions exceed the experimental critical load by $20 \%$.

\section{Influence of imperfections}

The previous results concerned multi-vaulted shells without imperfections. The next question is that of the influence of possible shape imperfections on the critical load. We performed a series of calculations to evaluate the influence of initial imperfections on buckling. In order to do that, we created an imperfect shell by adding to the initial perfect (multi-vaulted) geometry an imperfection, parallel to the elastic buckling mode under external pressure, with an amplitude of $10 \%$ of the thickness. Then we calculated the elastic-plastic nonlinear critical loads under uniform axial compression and under 
uniform external pressure for shells VM14 and VM22. The reductions observed in the critical loads did not exceed $3 \%$. We obtained similar results with an imperfection parallel to the buckling mode under axial compression. This led to the conclusion that these shells are relatively insensitive to initial imperfections, both in the case of axial compression and in the case of external pressure.

\section{Discussion}

We found that vaults lead to a significant increase in the buckling strength under uniform external pressure and also improve the resistance to axial compression. This type of shell is relatively insensitive to initial imperfections. The choice of the number of vaults also plays a role. The effect becomes significant once the number of vaults equals twice the Fourier buckling mode of the smooth cylinder under external pressure. The question then arises of the optimal choice of the number and depth of the vaults with regard to buckling strength under combined loading. This is the subject of the next section.

\section{The optimization procedure}

We carried out a systematic study of the effect of the number and depth of the vaults on the buckling strength under external pressure alone, under axial compression alone and, finally, under combined loading with $50 \%$ of the critical axial compression and $50 \%$ of the critical external pressure. In order to do that, we first assumed a constant vault depth d. We used the reference shell (Young's modulus 160,000 MPa and thickness $150 \mu \mathrm{m}$ ).

\section{Influence of the number of vaults $p$}

Under external pressure alone

The results of the linear elastic, nonlinear elastic and elastic-plastic calculations are given in Fig. 14. One can observe that the critical loads increase very rapidly beyond mode 10 (which corresponds to 20 vaults) and reach a factor 4 . Then, they continue to increase progressively with the number of vaults to reach a factor greater than 10 for 60 vaults. Let us note that, in this case, the nonlinear elastic estimates are very optimistic. Plasticity plays a significant role once the number of vaults exceeds 20 . Beyond 50 vaults, the critical load reaches a maximum of 10 times the Euler load.

\section{Under axial compression alone}

The results of the calculations are given in Fig. 15.

ASTER shells are less effective in terms of resisting axial compression. Nevertheless, beyond 20 vaults, the critical load is multiplied by two. Then it increases progressively with the number of vaults and reaches the Euler load for 80 vaults. In this case, taking nonlinearities into account leads to a significant decrease in the predicted critical load. Plasticity reduces it by about another $10 \%$.

\section{Under combined loading (50\% axial compression, $50 \%$ external pressure)}

The results of the calculations are given in Fig. 16.

For this loading combination, the linear and nonlinear elastic predictions are quite similar, but very optimistic. Taking plasticity into account plays a decisive role. 


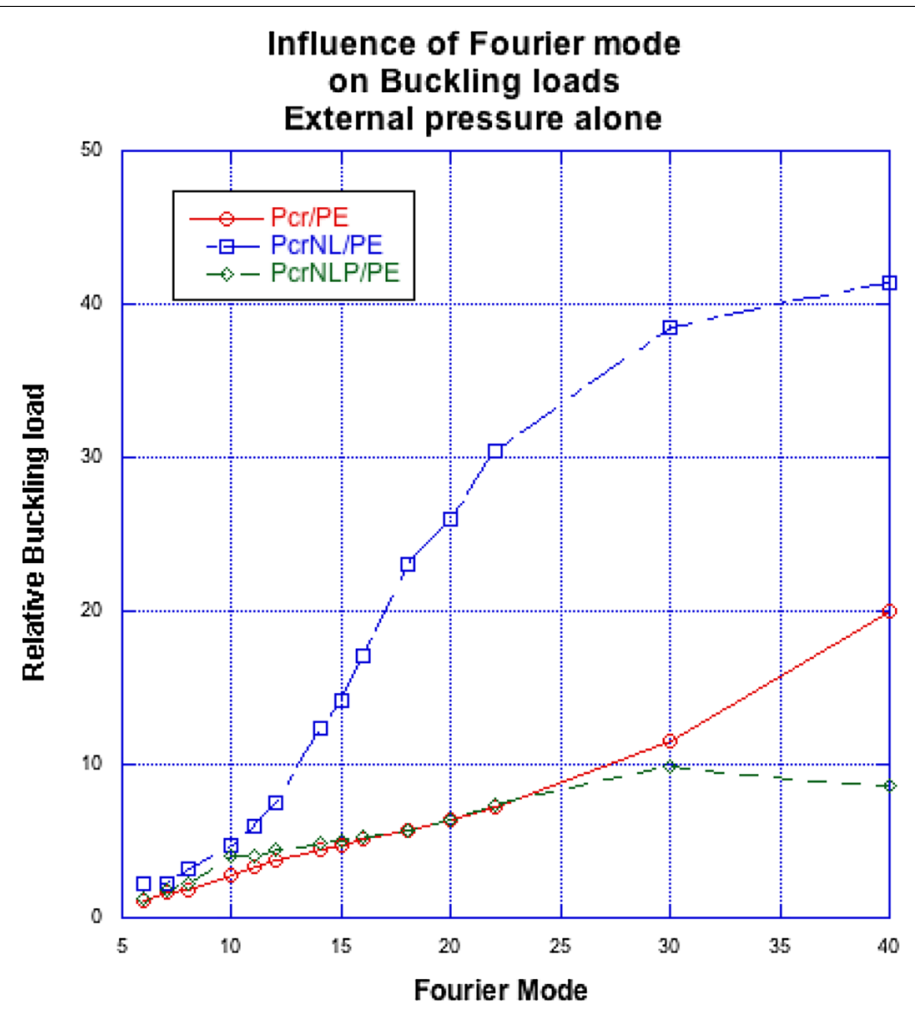

Fig. 14 ASTER VM shells: influence of the number of vaults on the buckling pressure

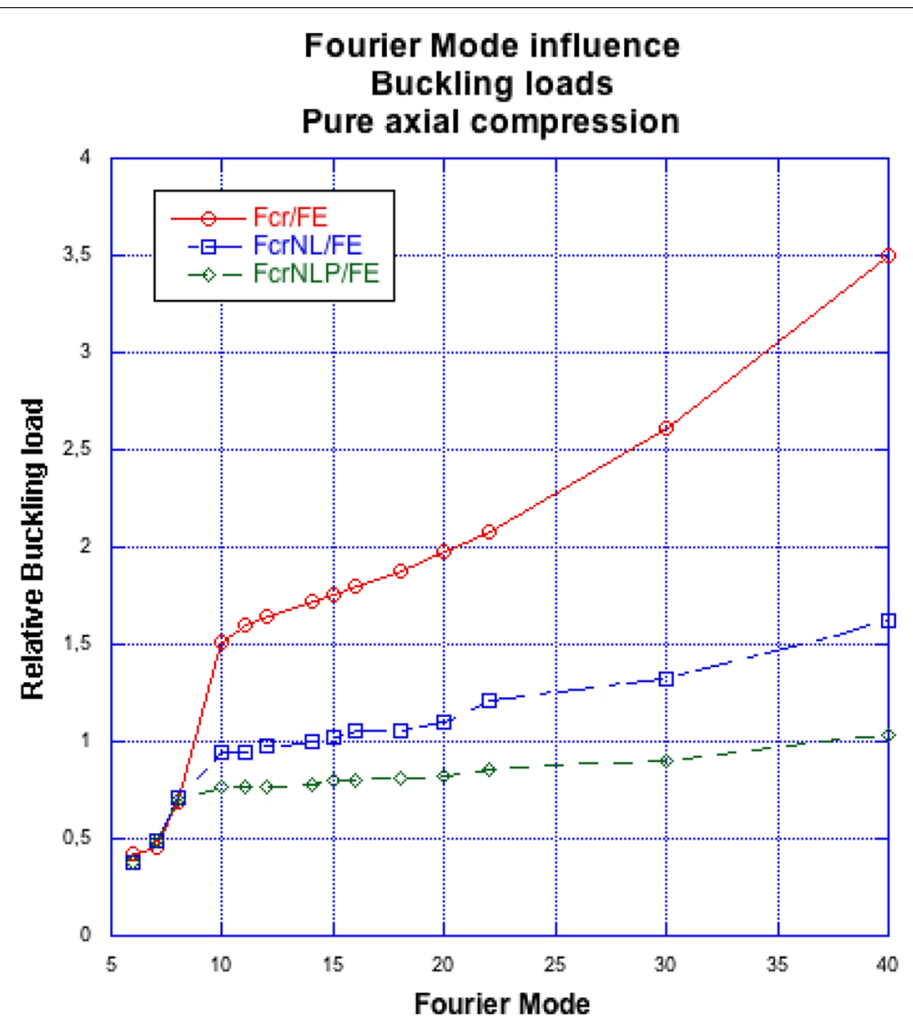

Fig. 15 ASTER VM shells: influence of the number of vaults on the axial compression buckling load 


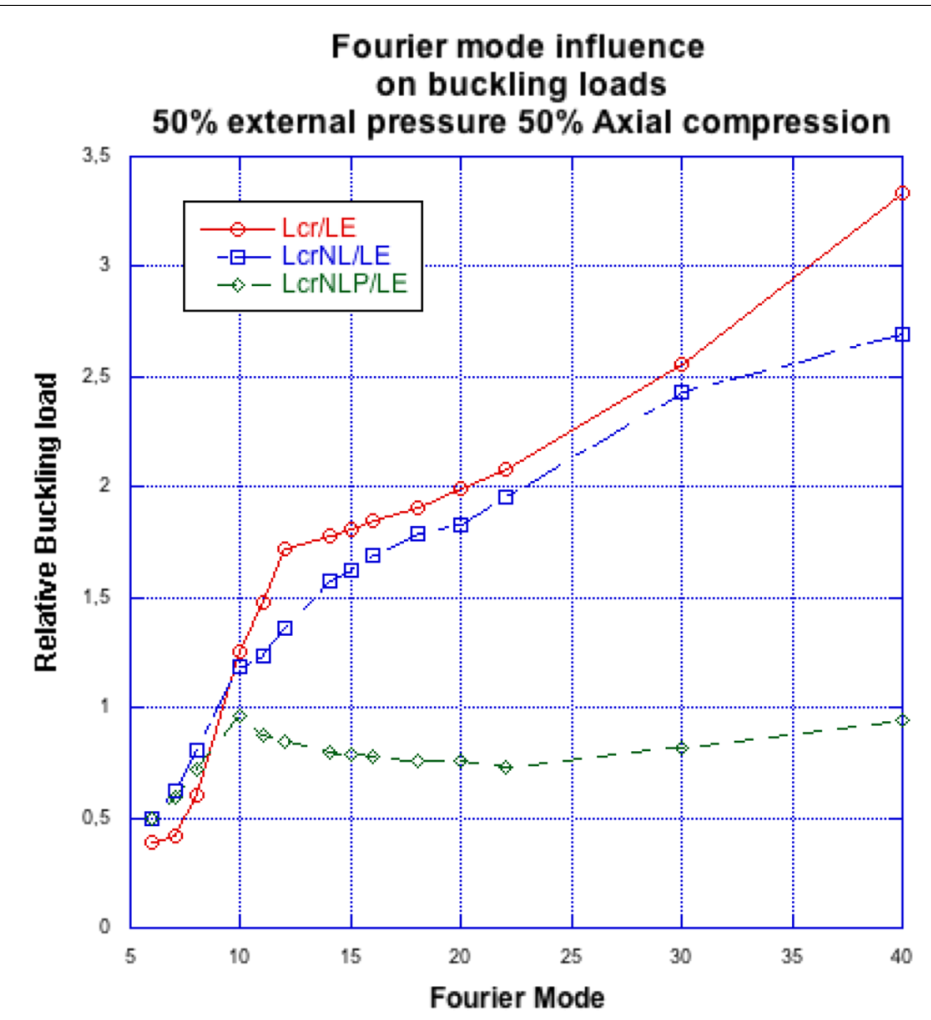

Fig. 16 ASTER VM shells: influence of the number of vaults on buckling under combined loading

However, one can observe that beyond 20 vaults the critical load is multiplied by two, then decreases by a maximum of $20 \%$.

\section{Influence of the vault depth d}

In this section, we study how the vault depth affects the improvement brought about by outward vaults. This presentation is limited to ASTER VM22 shells. We considered several ratios of the vault depth to the thickness of the shell. The evolution of the radius of curvature of the vault as a function of this ratio is shown in Fig. 17.

The calculation results for external pressure loading alone are given in Fig. 18. One can observe an improvement factor between 5 and 6 when the ratio $\mathrm{d} / \mathrm{h}$ becomes greater than 7.5. First, the nonlinear critical loads are greater than the linear critical loads. Plasticity limits the effectiveness of the shell when the ratio exceeds 10 .

Figures 19 and 20 show similar tendencies for axial loading and combined $50 \%$ external pressure and $50 \%$ axial compression loading. The nonlinear elastic and elastic-plastic critical loads become less than the Euler load when the vault depth exceeds 10 times the thickness.

Based on these results, we can conclude that the recommended vault depth is about 10 times the thickness. 


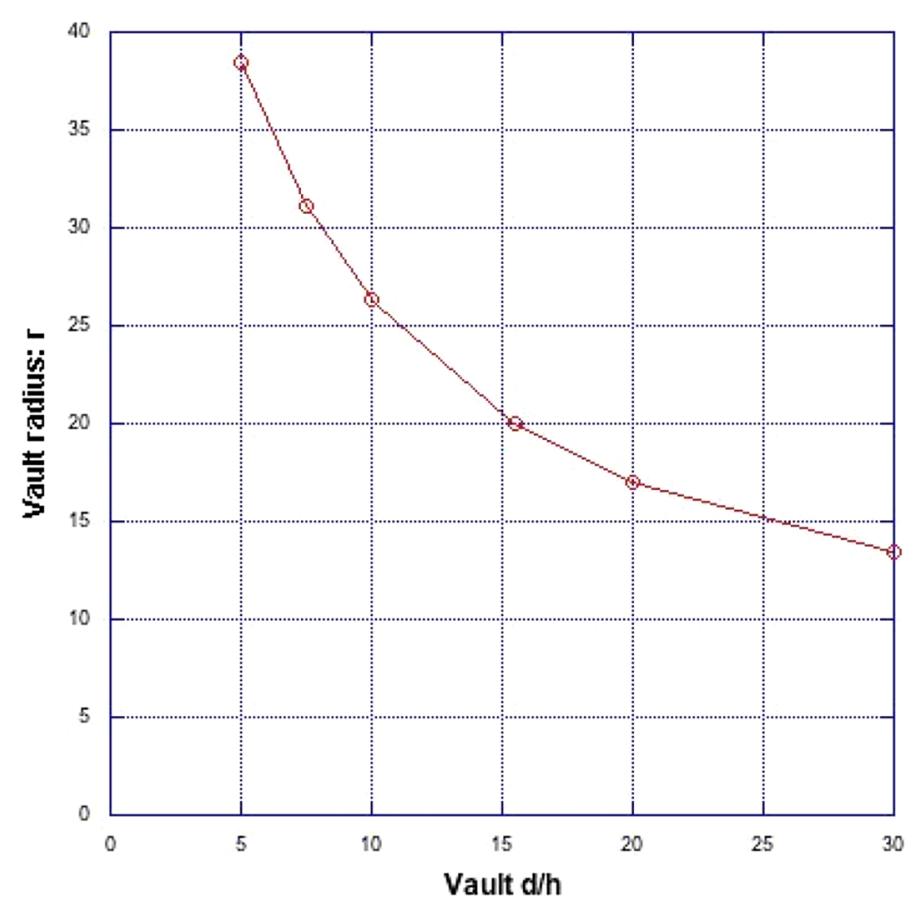

Fig. 17 ASTER VM22 shells: the relative vault depth as a function of the vault radius $r$

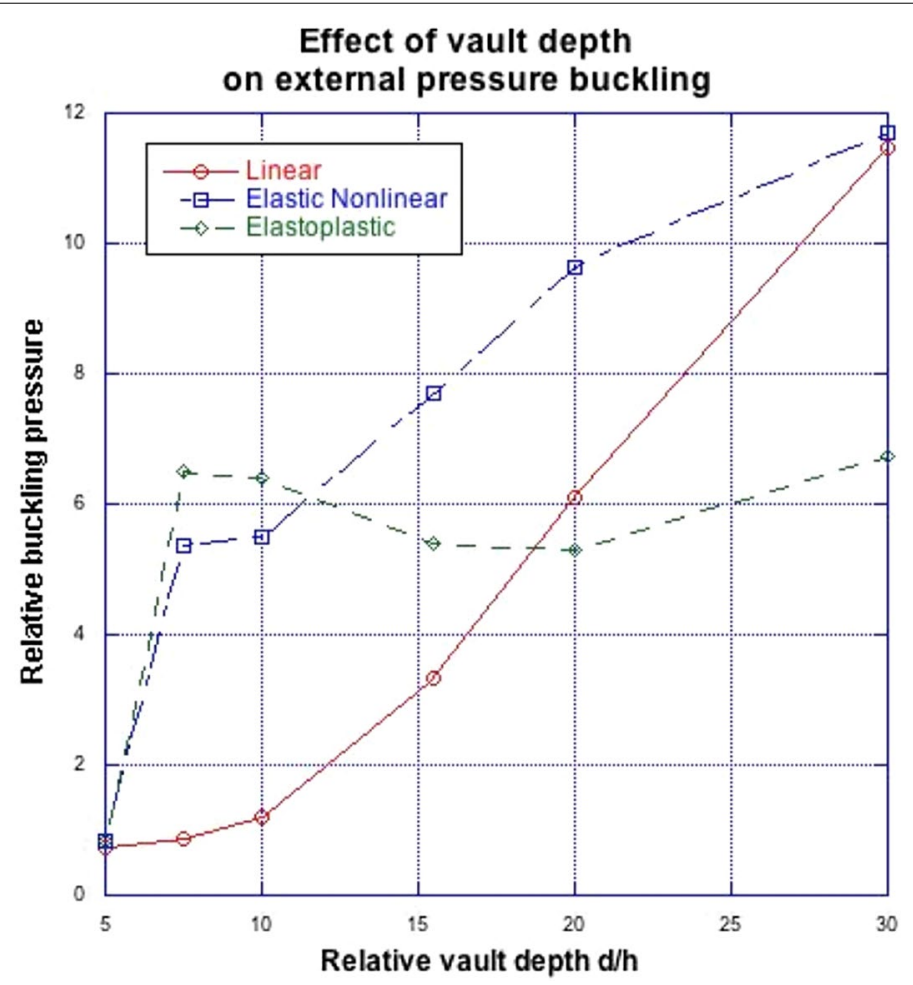

Fig. 18 ASTER VM22 shells: influence of the relative vault depth on the buckling load under external pressure 


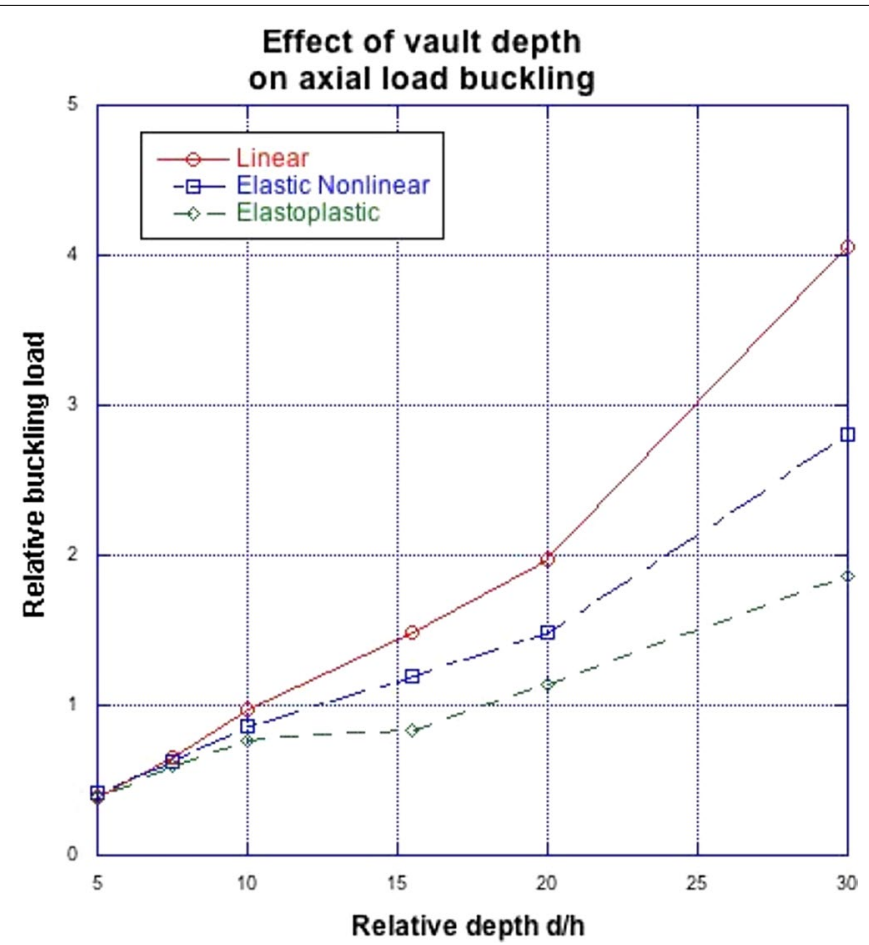

Fig. 19 ASTER VM22 shells: influence of the relative vault depth on the buckling load under axial compression

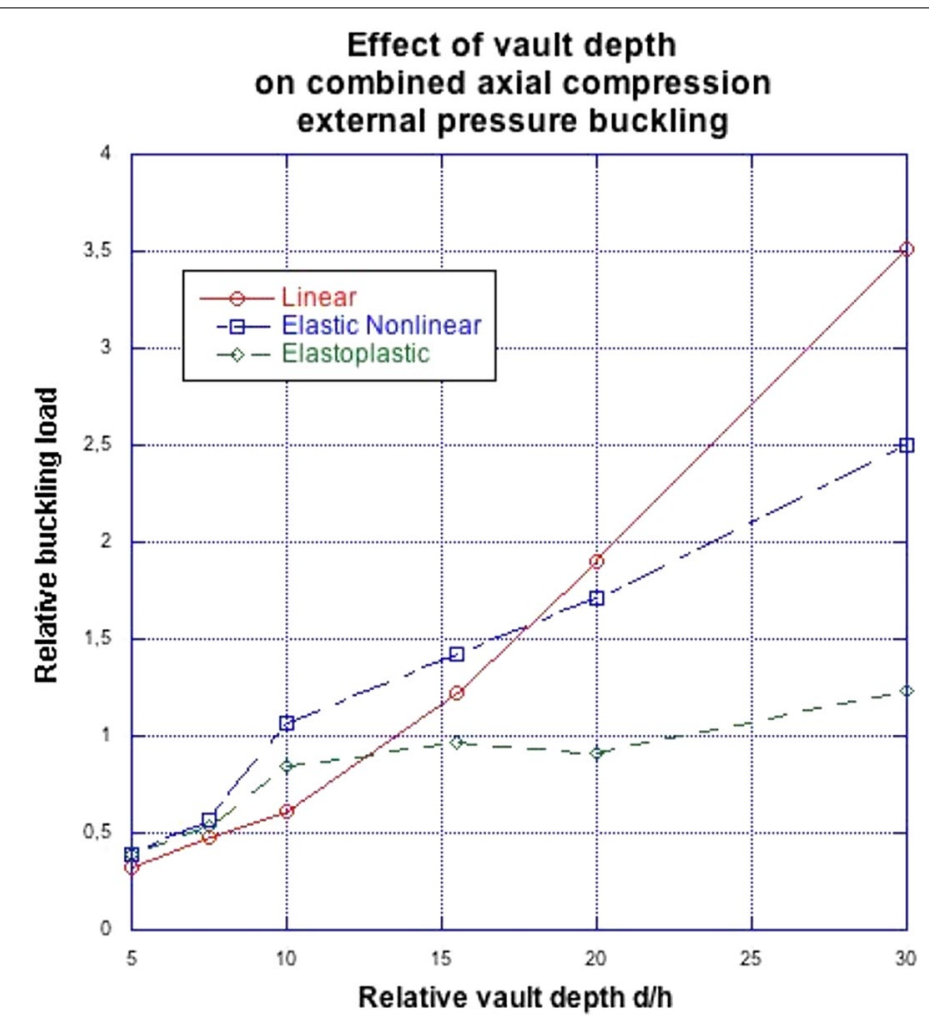

Fig. 20 ASTER VM22 shells: influence of the relative vault depth on the buckling load under combined loading 


\section{ASTER VM-22 shells: investigation of inward vaults}

In this section, we compare VM22 shells and shells defined with inverted vaults (i.e. with the concavity turned outwards) of the same depth $d$ or radius of curvature $r$. These new shells are designated as ASTER VM-22. The deformed buckling shape under axial compression is shown in Fig. 21.

The calculated buckling loads are compared in Table 14 .

One can observe that if one keeps the vault depth constant the outward vaults are more effective against buckling. Conversely, if one keeps the radius of curvature $r$ constant, the inward vaults are slightly better, especially in the axial compression case.

\section{Conclusions}

In summary, we developed shells which are relatively insensitive to imperfections and which resist buckling under external pressure much better than smooth cylindrical

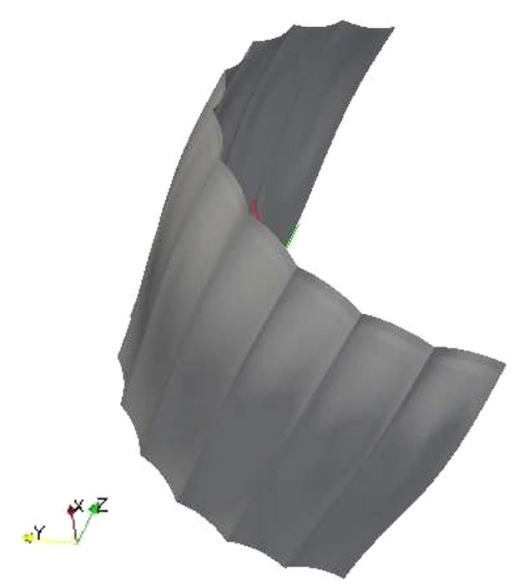

Fig. 21 ASTER VM-22: buckling mode under axial compression

Table 14 Comparison of the calculated buckling loads of ASTER VM22 and VM-22 shells

\begin{tabular}{|c|c|c|c|c|c|}
\hline Shell name & $\mathrm{d} / \mathrm{h}$ & $r(\mathrm{~mm})$ & $\frac{\Lambda_{E}}{P_{E}}$ & $\frac{\Lambda_{N L}}{P_{E}}$ & $\frac{\Lambda_{N L P}}{P_{E}}$ \\
\hline \multicolumn{6}{|c|}{ External pressure } \\
\hline VM 22 & 15.47 & 20 & 3.35 & 7.5 & 4.47 \\
\hline VM -22 & 15.47 & 20 & 4.96 & 3.5 & 4.6 \\
\hline VM -22 & 22.7 & 30 & 7.19 & 5.9 & 4.15 \\
\hline Shell name & $d / h$ & $r(\mathrm{~mm})$ & $\frac{\Lambda_{E}}{P F_{E}}$ & $\frac{\Lambda_{N L}}{P F_{E}}$ & $\frac{\Lambda_{N L P}}{P F_{E}}$ \\
\hline \multicolumn{6}{|c|}{$50 \%$ external pressure $50 \%$ axial compression } \\
\hline VM 22 & 15.47 & 20 & 1.22 & 1.43 & 0.97 \\
\hline VM -22 & 15.47 & 20 & 1.25 & 1.03 & 0.76 \\
\hline VM -22 & 22.7 & 30 & 2.12 & 1.53 & 0.90 \\
\hline Shell name & $d / h$ & $r(\mathrm{~mm})$ & $\frac{\Lambda_{E}}{F_{E}}$ & $\frac{\Lambda_{N L}}{F_{E}}$ & $\frac{\Lambda_{N L P}}{F_{E}}$ \\
\hline \multicolumn{6}{|c|}{ Axial compression } \\
\hline VM 22 & 15.47 & 20 & 1.48 & 1.19 & 0.92 \\
\hline VM -22 & 15.47 & 20 & 1.13 & 0.95 & 0.77 \\
\hline VM -22 & 22.7 & 30 & 1.79 & 1.48 & 1.15 \\
\hline
\end{tabular}


shells. Their axial compression strength is also better. These results require the use of a number of vaults at least equal to twice the Fourier mode number of the critical buckling mode of the smooth cylinder under external pressure. The recommended vault depth $\mathrm{d}$ is at least ten times the thickness. In addition, these shells are relatively insensitive to initial imperfections, which is an important advantage over the reference smooth cylinders. This type of shell can be manufactured relatively easily. The choice of vaults with their concavity turned inward seems to be slightly better when external pressures are predominant. The conclusions given in the paper take into account the load reduction effects due to plasticity, which play a significant role (all the more so when the stiffening effect is high). Therefore, one could improve the buckling strength of this type of shell much further by choosing materials with a high yield strength.

\section{Authors' contributions}

JFJ as provided the experimental results. AC has developped the FEM softwareand done all the computations. Both authors have read and approved the final manuscript.

\section{Author details \\ 1 SAFRAN-AREVA-Chair, LaMCoS UMR CNRS 5259, INSA-LYON, Universite de Lyon, 61 AV President Wilson, 69621 Villeur- banne, France. ${ }^{2}$ LaMCoS UMR CNRS 5259, INSA-LYON, Universite de Lyon, 61 AV President Wilson, 69621 Villeurbanne, France.}

\section{Competing interests}

The authors declare that they have no competing interests.

Received: 11 June 2015 Accepted: 1 October 2015

Published online: 13 October 2015

\section{References}

1. Donnell LH. A new theory for the buckling of thin cylinders under axial compression and bending. Trans ASME. 1934;56(11):795-806.

2. Windenburg DF, Trilling C. Collapse by instability of thin cylindrical shells under external pressure. Trans ASME. 1934;56(11):819.

3. Yoshimura Y. On the mechanism of buckling of a circular cylindrical shell under axial compression. Technical report. 1951.

4. Tennyson R. A note on the classical buckling load of circular cylindrical shells under axial compression. AIAA J. 1963;1(2):475.

5. Almroth B. Postbuckling behavior of axially compressed circular cylinders. AIAA J. 1963;1(3):630-3.

6. Almroth B, Holmes A, Brush D. An experimental study of the bucking of cylinders under axial compression. Exp Mech. 1964;4(9):263-70

7. Hoff NJ, Madsen WA, Mayers J. Postbuckling equilibrium of axially compressed circular cylindrical shells. AIAA J. 1966;4(1):126-33.

8. Tennyson R. Buckling modes of circular cylindrical shells under axial compression. AIAA J. 1969;7(8):1481-7.

9. Yamaki N. Influence of prebuckling deformations on the buckling of circular cylindrical shells under external pressure. AIAA J. 1969;7(4):753-5.

10. Yamaki N, Otomo K. Experiments on the postbuckling behavior of circular cylindrical shells under hydrostatic pressure. Exp Mech. 1973;13(7):299-304.

11. Miller CD. Buckling of axially compressed cylinders. J Struct Div. 1977;103(3):695-721.

12. Andrews K, England G, Ghani E. Classification of the axial collapse of cylindrical tubes under quasi-static loading. Int J Mech Sci. 1983;25(9):687-96.

13. Yamaki N. Elastic stability of circular cylindrical shells. In: Beckers A, Budianski B, Lauwerier HA, Koiter T, editors. North Holland Series in applied Mathematics and Mechanics. North Holland: Elsevier; 1984

14. Bushnell D. Computerized buckling analysis of shells. Mechanics of elastic stability, vol 9. Netherlands: Springer; 1985.

15. Teng J-G, Rotter JM. Buckling of pressurized axisymmetrically imperfect cylinders under axial loads. J Eng Mech. 1992;118(2):229-47.

16. Mandal P, Calladine C. Buckling of thin cylindrical shells under axial compression. Int J Solids Struct. 2000;37(33):4509-25.

17. Stein M. Some recent advances in the investigation of shell buckling. J Spacecr Rockets. 2003;40(6):908-14.

18. Rotter J. Cylindrical shells under axial compression. In: Teng JG, RotterM, editors. Buckling of thin metal shells. London: Spon; 2004. p. 42-87

19. Von Karman T. The buckling of thin cylindrical shells under axial compression. J Aeronaut Sci (Institute of the Aeronautical Sciences). 1941;8(8):303-13. 
20. Kempner J. Postbuckling behavior of axially compressed circular cylindrical shells. J Aeronaut Sci (Institute of the Aeronautical Sciences). 1954;21(5):354-63.

21. Donnell $L$, Wan C. Effect of imperfections on buckling of thin cylinders and columns under axial compression. J Appl Mech Trans ASME. 1950;17(1):73-83.

22. Donnell L. Effect of imperfections on buckling of thin cylinders under external pressure. J Appl Mech. 1956;23(4):569-75.

23. Gerard G. On the role of initial imperfections in plastic buckling of cylinders under axial compression. Aerospace Sci. 1962;29(6):744-5.

24. Sobel L. Effects of boundary conditions on the stability of cylinders subject to lateral and axial pressures. AIAA J. 1964;2(8):1437-40.

25. Hutchinson JW. Imperfection sensitivity of externally pressurized spherical shells. J Appl Mech. 1967;34(1):49-55.

26. Arbocz J, Babcock CD. The effect of general imperfections on the buckling of cylindrical shells. J Appl Mech. 1969;36(1):28-38.

27. Muggeridge D, Tennyson R. Buckling of axisymmetric imperfect circular cylindrical shells under axial compression. AIAA J. 1969;7(11):2127-31.

28. Hutchinson J, Koiter W. Postbuckling theory. Appl Mech Rev. 1970;23(12):1353-66.

29. Hutchinson J, Muggeridge D, Tennyson R. Effect of a local axisymmetric imperfection on the buckling behaviorof a circular cylindrical shell under axial compression. AIAA J. 1971;9(1):48-52.

30. Amazigo JC, Budiansky B. Asymptotic formulas for the buckling stresses of axially compressed cylinders with localized or random axisymmetric imperfections. J Appl Mech. 1972;39(1):179-84.

31. Sheinman I, Simitses GJ. Buckling analysis of geometrically imperfect stiffened cylinders under axial compression. AIAA J. 1977;15(3):374-82.

32. Sheinman I, Simitses G. Buckling and postbuckling of imperfect cylindrical shells under axial compression. Comput Struct. 1983;17(2):277-85.

33. Simitses GJ. Buckling and postbuckling of imperfect cylindrical shells: a review. Appl Mech Rev. 1986;39(10):1517-24.

34. Rotter JM, Teng J-G. Elastic stability of cylindrical shells with weld depressions. J Struct Eng. 1989;115(5):1244-63.

35. Calladine C. Understanding imperfection-sensitivity in the buckling of thin-walled shells. Thin Wall Struct. 1995;23(1):215-35.

36. Guggenberger W. Buckling and postbuckling of imperfect cylindrical shells under external pressure. Thin Wall Struct. 1995;23(1):351-66.

37. Gusic G, Combescure A, Jullien J. The influence of circumferential thickness variations on the buckling of cylindrical shells under external pressure. Comput Struct. 2000;74(4):461-77.

38. Batterman SC. Plastic buckling of axially compressed cylindrical shells. AIAA J. 1965;3(2):316-25.

39. Gellin S. Effect of an axisymmetric imperfection on the plastic buckling of an axially compressed cylindrical shell. J Appl Mech. 1979;46(1):125-31.

40. Sobel L, Newman S. Plastic buckling of cylindrical shells under axial compression. J Press Vessel Technol. 1980;102(1):40-4.

41. Andronicou A, Walker A. A plastic collapse mechanism for cylinders under uniaxial end compression. J Constr Steel Res. 1981;1(4):23-34

42. Hunt GW, Williams K, Cowell R. Hidden symmetry concepts in the elastic buckling of axially-loaded cylinders. Int J Solids Struct. 1986;22(12):1501-15.

43. ParkT-D, Kyriakides S. On the collapse of dented cylinders under external pressure. Int J Mech Sci. 1996;38(5):557-78.

44. Bardi F, Kyriakides S. Plastic buckling of circular tubes under axial compression? Part I: experiments. Int J Mech Sci. 2006;48(8):830-41.

45. Bardi F, Kyriakides S, Yun H. Plastic buckling of circular tubes under axial compression? Part II: analysis. Int J Mech Sci. 2006;48(8):842-54

46. Almroth BO. Influence of edge conditions on the stability of axially compressed cylindrical shells. AIAA J. 1966;4(1):134-40.

47. Shen H-S, Chen T-Y. Buckling and postbuckling behaviour of cylindrical shells under combined external pressure and axial compression. Thin Wall Struct. 1991;12(4):321-34.

48. Ning X, Pellegrino S. Imperfection-insensitive axially loaded thin cylindrical shells. Int J Solids Struct. 2015;62(1):39-51.

49. Ning X, Pellegrino S. Imperfection-insensitive axially loaded cylindrical shells. 2013. 54th AIAA/ASME/ASCE/AHS/ASC structures, structural dynamics and materialsconference, 8-11 April 2013, Boston, MA. Also see joint conference of Society of Engineering Science and ASME-AMD summer meeting.

50. Waeckel N. Imperfections geometriques initiales et instabilitTs de structures minces. PhD thesis, Universite Claude Bernard Lyon 1. 1984.

51. Waeckel N, Jullien PLJ-F. Experimental studies on the instability of initial geometrical imperfections. Special Publication (PVP), San Antonio, TX, USA. 1984;89:69-77.

52. Waeckel N, Cousin M, Combescure A, Carnoy E. Buckling of imperfect cylinders : a synthesis. Special Publication (PVP), San Antonio, TX, USA. 1984;89:78-85.

53. Waeckel, Kabore A, Cousin M, Jullien J-F. In: Buckling of cylindrical shells, Paper presented in 8th SMIRT Conference (August 1985), SMIRT, vol BL 1/2. Brussels; 1985.

54. Waeckel AK, Jullien J-F. Buckling of axially compressed imperfect cylinders and ring stiffened cylinders under external pressure. In: Wieringa H, editor. Experimental stress analysis, Proceedings of the VIIth international conference. Netherlands: Springer; 1986. p. 123-40.

55. Debbaneh, Jullien J-F, Reynouard J-M, Waeckel N. Corrugated cylindrical shells. In: Dubas P, Vandepitte D, editor. Proceedings of ECCS Colloquium on Stability of Plate and Shell Structurt's, Ghent University, 6-8 April 1987. p. 477-84.

56. Jullien J-F, Araar M. Towards an optimal shape of cylindrical shell structure under external pressure. In: Jullien J-F, editor. Buckling of shell structures, on land, in the sea Air. London: Elsevier applied science. 1991. p. 22-8. 
57. Limam A, Jullien J-F, Greco E, Lestrat D. Buckling of thin-walled cylinders under axial compression and internal pressure. In: Jullien J-F, editor. Buckling of shell structures, on land, in the sea Air. London: Elsevier applied science. 1991. p. 359-69.

58. Combescure A. Modeling elastic-plastic buckling of sandwich axisymmetric shells: on the limits of "shell" models and analytical solutions. Adv Model Simul Eng Sci. 2014;1:2.

59. Combescure A. Static and dynamic buckling of large thin shells. Nucl Eng Design. 1986;92:339-54.

\section{Submit your manuscript to a SpringerOpen ${ }^{\circ}$} journal and benefit from:

- Convenient online submission

- Rigorous peer review

- Immediate publication on acceptance

- Open access: articles freely available online

- High visibility within the field

- Retaining the copyright to your article 